\title{
Multiple Bank Lending, Creditor Rights, and Information Sharing*
}

\author{
ALBERTO BENNARDO ${ }^{1}$, MARCO PAGANO ${ }^{2}$ and \\ SALVATORE PICCOLO ${ }^{3}$ \\ ${ }^{1}$ University of Salerno and CSEF, ${ }^{2}$ University of Naples Federico II, CSEF, \\ EIEF, CFS and CEPR and ${ }^{3}$ Catholic University of Milan and CSEF
}

\begin{abstract}
Multiple bank lending induces borrowers to take too much debt when creditor rights are poorly protected; moreover, banks wish to engage in opportunistic lending at their competitors' expenses if borrowers' collateral is sufficiently risky. These incentives lead to credit rationing and positive-profit interest rates, possibly exceeding the monopoly level. If banks share information about past debts and seniority via credit reporting systems, the incentive to overborrow is mitigated: interest and default rates decrease; credit access improves if the value of collateral is not very volatile, but worsens otherwise. Recent empirical studies report evidence consistent with these predictions. The article also shows that private and social incentives to share information are not necessarily aligned.
\end{abstract}

JEL Classification: D73, K21, K42, L51

\section{Introduction}

In most countries, firms tend to borrow from several banks: this applies to more than $85 \%$ of the European companies (Ongena and Smith, 2000), with even small and medium-sized firms patronizing several lenders (Detragiache, Garella, and Guiso, 2000; Farinha and Santos, 2002). This pattern is also found in the USA. Yet, Petersen and Rajan (1994) document that "borrowing from multiple lenders increases the price and reduces the availability of credit" (p. 3). We argue that actual or potential multiple bank lending can

\footnotetext{
* We are indebted to Andrea Attar, Martin Brown, Peter DeMarzo, Paolo Garella, Yaron Leitner, David Martimort, Uday Rajan, Ilya Segal, Lucy White, and an anonymous referee for insightful suggestions. Useful comments were also provided by participants to the European Summer Symposium in Financial Markets, the CSEF-IGIER Symposium on Economics and Institutions, the 2009 Barcelona ESEM, the 2010 Meetings in Economics at Velia, the 2012 EFA Meetings, and seminars in EIEF, EUI, Lausanne, LUISS, Milan, Paris School of Economics, Tor Vergata (Rome), and Zurich for their comments. A former version of this article was circulated under the title "Information Sharing with MultipleBank Lending". We acknowledge the financial support of the Italian Ministry of University and Research (MIUR) and of the Einaudi Institute for Economics and Finance (EIEF).
} 
have these adverse effects because it induces both borrowers and lenders to behave opportunistically, whenever the value of collateral is volatile and creditor rights are not well protected.

When people can borrow from several banks and are protected by limited liability, they have the incentive to overborrow: each additional dollar of a borrower's debt raises default probability vis-à-vis all lenders. Moreover, lenders themselves may behave opportunistically, offering extra credit to customers already indebted with competing banks, while protecting their own claims via high interest rates. Such opportunistic lending may arise because banks are only partially informed on the credit conditions offered by their competitors, as no bank can observe all outstanding loan offers when deciding whether to accept an entrepreneur's credit application. And customers may wish to avail themselves of the extra credit extended by opportunistic banks to undertake larger and less efficient projects that generate private benefits for them ("empire-building" activities). To protect themselves against the contractual externalities created by such opportunistic behavior, lenders may ration credit and increase interest rates. ${ }^{1}$

Our article brings out the implications of these externalities for credit market equilibrium, and investigates how their intensity is affected by information sharing among lenders (credit reporting), via private credit bureaus or public credit registries. We show that, with no information sharing and poor creditor rights protection, banks deny credit to some applicants, and borrowers default strategically when their collateral value is depressed. If the value of collateral is not too volatile, information sharing improves credit market performance: it reduces interest rates and default rates, and it eliminates rationing. But if the value of collateral is very volatile, information sharing induces the credit market to freeze. This is because information sharing has two opposite incentive effects: on one hand, it allows lenders to better protect themselves against borrowers' opportunistic behavior, and therefore to charge lower rates and expand lending; on the other hand, it enables opportunistic lenders to better target those borrowers to whom they can profitably lend at their competitors' expenses. When collateral value is not very volatile, the first effect prevails; when it is, the second does, because risk shifting becomes more profitable.

Our model of the credit market is very stylized. A representative entrepreneur can borrow from several banks to carry out either a small investment project or a large but less profitable one. Yet, he may wish to undertake the

1 In principle, multiple bank lending may also have beneficial effects by allowing banks to achieve better risk sharing and thereby offer cheaper loans. For simplicity, in the analysis we abstract from this aspect. 
large project because he can appropriate some of its revenue as private benefit, to an extent that depends on the degree of creditor protection. The entrepreneur's collateral is risky, so that he may default if its value happens to be low. Lenders cannot observe which project is actually carried out by borrowers, so that they face a common-agency problem. ${ }^{2}$

Depending on the severity of this agency problem, three equilibrium outcomes can emerge in the absence of information sharing. First, when creditor rights are well protected, entrepreneurs get loans at the zero-profit interest rate and undertake the small and efficient project.

Second, at intermediate levels of creditor protection, two types of equilibria exist. One features rationing and strategic default: credit applicants are funded with probability lower than one, but they may succeed in borrowing opportunistically from more than one bank. Interest rates exceed the cost of funding, and new lenders do not enter for fear of lending to overindebted entrepreneurs. The other is an equilibrium where loans are granted at positive-profit rates, all entrepreneurs are served by a single bank, and competitors refrain from undercutting it for fear that the entrepreneur may borrow even further and default. While the latter parallels the equilibrium in Parlour and Rajan (2001), the rationing equilibrium is novel and inherently related to multibank lending. In the positive-profit equilibrium without rationing, instead, credit relationships are exclusive and multibank lending only plays a latent role.

Thirdly, if creditor rights are very poorly protected and collateral values are highly volatile, the only surviving equilibria are those with rationing or market freeze. In this region, if the market does not freeze, different groups of lenders offer credit at different terms, possibly at "usurious rates" that exceed even the monopoly level.

When instead banks share information about their clients' outstanding debts and seniority, they can condition their loans on the borrowers' contractual history, and thereby better guard against opportunistic lending. Hence, information sharing expands the region where lending can be only offered at zero-profit rates and efficiency prevails; if entrepreneurs' collateral is not too volatile, information sharing eliminates rationing and lowers interest rates. But beside this "bright side", credit-reporting systems also have a "dark side" that emerges when the value of borrowers' collateral is

\footnotetext{
2 Bernheim and Whinston (1986a, 1986b) offer the first general treatment of this class of models. Kahn and Mookherjee (1998) specialize the analysis to the case of insurance contracts, but consider a model with sequential offers. Segal and Whinston (2003) and Bisin and Guaitoli (2004) consider a more general contracting space by introducing latent contracts and menus. Martimort and Stole $(2003,2009)$ study common agency models with adverse selection and menus.
} 
very volatile. In this case, lenders have a strong incentive to bet on the appreciation of collateral by providing extra loans to low-debt customers of other banks. Credit-reporting systems may facilitate such opportunistic behavior, allowing lenders to target more easily low-debt customers, and thus further exacerbate rationing.

We also briefly investigate whether information sharing can be expected to arise spontaneously whenever socially beneficial, if banks can initially commit to share information with competitors, for instance via a credit bureau. We find that in general this outcome is not guaranteed: in the region where information sharing eliminates incentives to opportunistic borrowing, there are both efficient and zero-profit equilibria where banks choose to share information, and inefficient and positive-profit equilibria where they do not. Which equilibrium is selected depends on how entrepreneurs select the bank they patronize when several banks offer the same rates: if borrowers tend to be "loyal" to a specific bank, no information is shared in equilibrium. In this case, government intervention to induce lenders to share information is warranted.

In most of the paper, banks share information only about entrepreneurs' past indebtedness. However, we also extend the model to the case where information sharing allows banks to monitor the subsequent indebtedness of their clients. In this instance, the benefits of information sharing are amplified, and its "dark side" disappears altogether. ${ }^{3}$

Taken together, our model produces three main testable implications. First, absent information sharing, rationing can emerge if collateral values are volatile and credit protection is poor; this rationing is associated with high interest and default rates, consistent with evidence from developing countries (Mookherjee, Ray, and Ghosh, 2000). If different classes of borrowers post collateral with observably different riskiness, the model predicts that those whose collateral is sufficiently risky are randomly rationed while those with safe collateral are not, so that the former are subject to a tighter credit standard than the latter, in the form of greater probability of credit denial. This is consistent with the panel-data evidence reported by Degryse, Ioannidou, and von Schedvin (2011), who investigate the externalities between lenders by studying the incumbent lender's response to new loans to its customers provided by competitors: they find that the greater the volatility of collateral, the stronger is the incumbent's adverse interest rate and credit tightening response. This aligns with our prediction that the

\footnotetext{
3 In this case, information sharing becomes effectively equivalent to exclusivity. A comparison between exclusive and nonexclusive lending is provided by Bisin and Guaitoli (2004) and Attar, Campioni, and Piaser (2006), among others.
} 
externality arising from nonexclusive lending only arises when the value of collateral is sufficiently volatile.

Second, we show that when banks share information about past debts (not merely about delinquencies), they end up reducing default and interest rates, particularly for borrowers that are informationally opaque and have risky collateral. These predictions square with an expanding body of evidence, based on cross-country aggregate data (Pagano and Jappelli, 1993; Jappelli and Pagano, 2002; Djankov, McLiesh, and Shleifer, 2007) and on microeconomic data (Galindo and Miller, 2001; Brown, Jappelli, and Pagano, 2009; de Janvry, McIntosh, and Sadoulet, 2010; Doblas-Madrid and Minetti, 2013).

Third, information sharing about past debts is predicted to increase credit access by eliminating rationing, for moderate levels of creditor protection and collateral volatility. But information sharing may exacerbate rationing in situations where creditor rights are poorly protected and collateral values are very uncertain, as in some developing countries or more generally at times of great turbulence like financial crises, as found by Herzberg, Liberti, and Paravisini (2011) in their study of the extension of Argentine credit reporting coverage.

On the whole, our analysis explains why credit bureaus and registries so often pool data about past debts and report clients' total indebtedness to banks, rather than just reporting past delinquencies and borrowers' characteristics. This activity by credit-reporting systems only makes sense in the context of multiple bank lending. Hence, this article complements earlier models of information sharing in credit markets, which typically assume exclusive lending. These models show that sharing data on defaults and customers' characteristics enables banks to lend more safely, overcoming adverse selection (Pagano and Jappelli, 1993), or promoting borrowers' effort to repay loans (Padilla and Pagano, 1997, 2000). An exception is the model by Bar-Isaac and Cuñat (2012), who study how information sharing by a subset of banks affects competitive outcomes in the absence of exclusivity. In their setting, heterogeneous borrowers can raise funds both from banks that share information and from "hidden" lenders in the informal sector: borrowing from the latter allows them to conceal bad results from their banks and therefore ends up constraining the loan contracts that banks are willing to offer. ${ }^{4}$

\footnotetext{
4 In a sequential common agency game with adverse selection, Calzolari and Pavan (2006) also analyze the conditions under which information sharing between principals may enhance efficiency.
} 
Finally, our article also relates to the vast literature on the determinants of credit rationing (e.g., Stiglitz and Weiss (1981), Besanko and Thakor (1987) and Bester (1987), among others), which all share a common feature: rationing arises because the interest rate charged by banks is "too low" to enable the credit market to clear but no bank attempts to raise it, fearing to worsen the pool of loan applicants. In contrast, in our model banks react to the danger of opportunistic lending both by rationing and by raising their rates above the zero-profit level, in some cases even beyond the monopoly level. Another distinctive feature of the credit rationing due to multibank lending is that it is more likely to arise when collateral value is volatile, which instead is inconsequential in the Stiglitz-Weiss (1981) and in the Holmstrom-Tirole (1997) model.

The article is structured as follows. Section 2 lays out the model. Section 3 analyzes the incentives to overborrowing in the regime with no information sharing. Sections 4 and 5, respectively, characterize equilibria without and with information sharing about borrowers' indebtedness and seniority structure. Section 6 argues that the model is robust to change in assumptions concerning the timing of offers and the distribution of bargaining power, and presents two extensions: banks' incentives to share information, and banks' commitment to disclose subsequent borrowers' exposure. Section 7 concludes. Proofs are provided in the Appendix.

\section{The Model}

We consider banks that compete by offering credit to a representative entrepreneur. The interest rate at which banks raise funds is standardized to zero. The entrepreneur is risk-neutral and can undertake a small project or a large one, requiring an investment $x$ or $2 x$ respectively. The two projects have revenues $y_{S}$ and $y_{L}$, with $y_{L}>y_{S}$, so that the net surplus is $v_{S} \equiv y_{S}-x$ or $v_{L} \equiv y_{L}-2 x$. The small project generates a larger surplus than the large one $\left(v_{S}>v_{L}\right)$, so that the rate of return is decreasing in the scale of the project. Due to limited managerial capacity, each entrepreneur can undertake at most one project.

The entrepreneur has no resources when projects are started, and can apply for loans at multiple banks, indexed by $b$. A credit contract $c_{b}=\left(l_{b}, r_{b}\right)$ issued by bank $b$ consists of a loan $l_{b}$ and a repayment $r_{b}$.

The contractual environment is shaped by the following assumptions:

(A1) Hidden action. Lenders cannot verify the size of the borrower's project, and thus whether he takes additional lending from other banks. However, any loan that is not invested in a project is 
returned to the banks: the entrepreneur cannot consume funds that are not used for investment.

(A2) Limited enforcement. The entrepreneur is protected by limited liability and can appropriate a fraction $\phi \in(0,1]$ of the revenue of the large project, which cannot be seized by lenders in case of default.

(A3) Uncertain future wealth. The entrepreneur has a stochastic endowment $\tilde{w}$ that equals either $1+\sigma$ or $1-\sigma$ with equal probability. We normalize its expected value $\bar{w}$ to 1 and assume that its standard deviation $\sigma$ lies in the interval $[0,1]$.

(A4) Costly state verification: The realization of future wealth $\tilde{w}$ is unverifiable except in case of default.

(A5) Liquidation in bankruptcy: We assume that, in case of default, creditors are paid according to their seniority.

(A6) Unviability of the large project: The expected amount that the entrepreneur can pledge upon undertaking the large project does not cover the project's cost: $(1-\phi) y_{L}+1-2 x<0$ - that is, $\phi \geq \phi_{0} \equiv\left(v_{L}+1\right) / y_{L}$.

Assumptions (A1) and (A2), together with multiple bank lending, create a moral hazard problem: after borrowing an amount $x$, the entrepreneur may want to borrow an additional $x$ and undertake the large project, so as to appropriate a share $\phi$ of its revenue. This can damage lenders, since the large project yields less than the small one, and its return can be partially appropriated by the entrepreneur. The fact that the entrepreneur can divert resources from the large project, but not from the small one, captures the idea that investment may be driven by an "empire building" motive: entrepreneurs may wish to undertake unprofitable investments if they know that control over a larger company generates more private benefits for them, at their creditors' expenses. Assumption (A1) also requires that banks can deter diversion of unused funds to private consumption: this rules out another form of moral hazard, which would further complicate the model. The idea is that banks can observe whether, once they make a loan to an entrepreneur, the loan is used for consumption rather than investment.

Assumption (A3) captures the riskiness of the value of the entrepreneur's personal assets (e.g., his house) or his firm's asset base (e.g., land or equipment), which can be pledged as collateral to expand the borrower's debt capacity. Collateral risk exacerbates the moral hazard problem explained above, because it allows the borrower to default when collateral value is low, thereby reducing the amount that on average banks can seize from him (for a given pledged interest rate). This problem would be completely internalized if the entrepreneur could borrow only from a single bank, but 
under multiple bank lending it generates a risk-shifting opportunity between banks: a bank may find it profitable to fund the large project at a sufficiently high rate, because this insulates it from the losses arising in the default state, and off-loads them onto its competitors. Collateral risk is a novel ingredient relative to the relevant literature: most of our novel results are traceable to this new assumption, which deeply changes the nature of banking competition by creating scope for opportunistic lending absent from former models, such as Parlour and Rajan (2001). As shown by the subprime crisis, the volatility of collateral values can have a dramatic effect on credit provision to households and firms, even in countries that feature relatively good protection of creditor rights; moreover, Degryse, Ioannidou, and von Schedvin (2011) document that it exacerbates the negative externality between nonexclusive lenders, precisely as predicted by our model.

Assumption (A4) rules out financing contracts contingent on future wealth, and implies pure debt financing: verifying borrowers' wealth is so costly as to be worthwhile only upon default..$^{5}$ Assumption (A5) is made for realism, since in the presence of collateral most legal systems allow for seniority rules in case of default; however, our results qualitatively hold also under pro rata repayment.

Finally, assumption (A6) is made to simplify the analysis and focus on the most novel equilibria: if also the large projects were assumed to be viable, there would be an additional parameter region where the entrepreneur undertakes the large project with certainty - a type of inefficient equilibria similar to those already studied by Bizer and DeMarzo (1992). It is to be noticed that, even if the large project is not financially viable, the entrepreneur may still want to carry it out solely to extract private benefits at the expense of (some) lenders. Hence, banks must worry that their loan offers might lead to opportunistic behavior, as we shall see below. Moreover, this assumption does not imply that an entrepreneur picking the large project will invariably default: he will default on average, but may repay the loan in the good state.

\subsection{INFORMATION-SHARING REGIMES AND TIMING OF THE GAME}

We will study two alternative regimes of communication between banks:

- under no information sharing, banks can verify neither borrowers' total indebtedness nor the seniority structure of their debt;

5 This assumption is common to many contributions in the literature, for instance Bizer and DeMarzo (1992) and Bisin and Rampini (2006). It also rules out insurance contracts with which entrepreneurs can hedge against their wealth risk. 
- under information sharing, banks can verify borrowers' indebtedness, that is, their total pledged repayment, its breakdown among creditors, and their seniority. ${ }^{6}$

This captures a common feature of credit reporting systems, which allow lenders to interrogate credit bureaus or registers about the exposure of prospective clients upon receiving a loan application.

We represent market interactions as a game in which banks issue loan contracts simultaneously, the entrepreneur applies for these loans, and each bank accepts or rejects the received loan application. Then, the entrepreneur signs the loan contracts sequentially: the sequence that he chooses pins down the seniority of each bank that accepted his application. The terms of the contracts hinge on the information sharing regime. Without information sharing, at the stage when contracts are signed, banks cannot verify how much the entrepreneur has already committed to repay by signing previous loan contracts, while they can do so with information sharing. Therefore, information sharing allows banks to include in their contracts a covenant conditioning the loan on the debt exposure that the entrepreneur already has toward more senior lenders, while no such covenant can be enforced without information sharing.

After the contracting stage, the entrepreneur invests in the small or in the large project. Finally, nature determines the projects' payoffs and the value of the entrepreneur's collateral, and loans are repaid or default occurs. The precise description is shown in Figure 1.

At stage $t=1$, not all the offers posted by banks are observable by their competitors: some banks post public loan offers, while others post private offers, which are visible to the entrepreneur but not to competing banks (see the beginning of the appendix for details). The assumption that some loan offers are publicly visible is in line with real-world experience, while the "secrecy" of other offers need not be taken literally: it is meant to capture the idea that some banks may manage to renegotiate their loan contracts without other banks realizing it, as in McAfee and Schwartz (1994). The secret offers in our simultaneous-offers setup play the same role that future offers would play in a model where loan offers are sequential and there is no last stage, so that new loan contracts can be offered in the future by competitors. ${ }^{7}$

\footnotetext{
${ }^{6}$ We also discuss a more extensive form of information sharing, whereby banks can request credit reports also after the loan application stage, in order to monitor subsequent changes in clients' exposure: this enables lenders to use covenants, so as to make repayments contingent on subsequent borrowing.

7 Indeed, in a previous version of this article its results were proved in a more complex dynamic setting where banks issue contracts sequentially and there is no last stage, so that
} 


$\begin{array}{llllll}\begin{array}{l}\text { Banks } \\ \text { issue } \\ \text { loan } \\ \text { contracts }\end{array} & \begin{array}{l}\text { The } \\ \text { entrepreneur } \\ \text { applies for } \\ \text { the banks } \\ \text { contracts }\end{array} & \begin{array}{l}\text { Banks } \\ \text { accept or } \\ \text { reject loan } \\ \text { applications }\end{array} & \begin{array}{l}\text { The } \\ \text { entrepreneur } \\ \text { attributes } \\ \text { seniority } \\ \text { rights }\end{array} & \begin{array}{l}\text { The } \\ \text { entrepreneur } \\ \text { picks the } \\ \text { investment } \\ \text { project }\end{array} & \begin{array}{l}\text { Collateral value } \\ \text { and project returns } \\ \text { are realized, and } \\ \text { loans are repaid or } \\ \text { default occurs }\end{array} \\ & t=2 & t=3 & t=4 & t=5 & t=6\end{array}$

Figure 1. Time line.

In either case (renegotiation of existing loans or issuance of future ones), each bank must take into account that undetectable, opportunistic lending can reduce the repayment ability of the entrepreneur below the level that can be inferred by simply looking at observable offers. ${ }^{8}$ Since we need to ensure that no bank knows all the offers made by competitors, we assume that there are at least two banks posting private offers: if there was just one such bank, it would know the offers of all its competitors.

At stage $t=2$, the entrepreneur applies simultaneously to as many banks as he wishes. The assumption of simultaneous application only simplifies the description of strategies compared to sequential applications.

At stage $t=3$, each bank $b$ accepts the entrepreneur's application with probability $\alpha_{b} \in[0,1]$. This probability can be reinterpreted as the fraction of credit applicants who receive credit, if the assumption of a single representative entrepreneur is replaced with that of a continuum of identical entrepreneurs.

At stage $t=4$, the entrepreneur determines the seniority of the banks that lend to him, for instance by signing their contracts sequentially. Banks ignore their precise seniority in the absence of information sharing: even though seniority rights exist, banks do not know their precise position in the seniority ladder. Instead, when they share information about the entrepreneur's indebtedness, banks can infer their respective seniority.

\section{1.a. Strategies and payoffs}

When deciding on a loan application at stage $t=3$, in the absence of information sharing each bank only knows the contracts issued by competitors making public offers. In contrast, with information sharing, a bank also knows the entrepreneur's past indebtedness, that is, both his total pledged

no bank knows the whole set of offers available to the entrepreneur when it decides whether to accept loan applications.

${ }^{8}$ It is important to realize that information sharing is compatible with secret offers, since it refers to indebtedness, and therefore to actual loans, and not loan offers. 
repayment and its breakdown across loans. Bank $b$ 's strategy is a contract offer $c_{b}=\left(l_{b}, r_{b}\right)$ and an acceptance probability $\alpha_{b}$ conditional on the information known to the bank up to $t=3$. Specifically, the acceptance probabilities with no information-sharing can be conditioned only on rivals' public offers - that is, on the contract offers made by banks 1 and 2. In contrast, with information sharing each bank knows not only the public offers made by banks 1 and 2 but also the amount of debt already taken by the entrepreneur when he patronizes this bank to sign its contract. Hence, in this regime, banks's acceptance decisions can be conditioned on both these pieces of information. The entrepreneur's strategy is a set of loan applications, the seniority structure of agreed loans, and a choice of project size $n \in\{S, L\}$.

The players' payoffs depend on the agreed loan contracts, their seniority structure, and the choice of the project size. In particular, the entrepreneur's payoff depends on his final indebtedness $R$ arising from the loan contracts agreed upon, that is, the total repayment pledged to all the banks with whom he signed contracts:

$$
R \equiv \sum_{b \in B} r_{b}
$$

where $B$ is the set of banks that sign contracts with the entrepreneur, and $r_{b}$ denotes the repayment pledged on a loan agreed at stage $t=4$.

Payoff of the entrepreneur. The final payoff accruing to the entrepreneur with project $n \in\{S, L\}$ and wealth $\tilde{w}$, upon agreeing to repay $R$ is

$$
u_{n}(\tilde{w}, R) \equiv \phi_{n} y_{n}+\max \left\{0,\left(1-\phi_{n}\right) y_{n}+\tilde{w}-R\right\},
$$

where by assumption $\phi_{S}=0$ and $\phi_{L}=\phi$, because the entrepreneur can extract private benefits only from the large project. The second term in the previous expression captures the fact that, in case of default, the entrepreneur is protected by limited liability, and that default occurs if the realized value of pledgeable wealth falls short of the total pledged repayment, that is, $\left(1-\phi_{n}\right) y_{n}+\tilde{w}<R .{ }^{9}$ Recalling that the two realizations of $\tilde{w}$ are equally likely and that $\mathrm{E}(\tilde{w})=1$, the expected utility of the entrepreneur can be written as

$$
\begin{aligned}
\mathrm{E}\left[u_{n}(\tilde{w}, R)\right]= & \phi_{n} y_{n}+\frac{1}{2} \max \left\{0,\left(1-\phi_{n}\right) y_{n}+1-\sigma-R\right\} \\
& +\frac{1}{2} \max \left\{0,\left(1-\phi_{n}\right) y_{n}+1+\sigma-R\right\} .
\end{aligned}
$$

\footnotetext{
9 This definition of default implies that, whenever the total debt of the entrepreneur falls short of his pledgeable wealth but exceeds the project's payoff, the entrepreneur sells the collateral (or part of it) and uses the corresponding earnings to avoid default.
} 
For instance, if the entrepreneur borrows $x$ only from bank 1, this expression equals

$$
\mathrm{E}_{\tilde{w}}\left[u_{S}\left(\tilde{w}, r_{1}\right)\right]=\frac{1}{2} \max \left\{0, y_{S}+1-\sigma-r_{1}\right\}+\frac{1}{2} \max \left\{0, y_{S}+1+\sigma-r_{1}\right\} .
$$

If the repayment owed to the bank is less than the project's revenue $\left(r_{1} \leq y_{S}\right)$, there is no default and the entrepreneur's payoff becomes $y_{S}+1-r_{1}$. If instead the entrepreneur borrows $x$ from two banks, say bank 1 and bank 2 , and undertakes the large project, his expected utility is

$$
\begin{aligned}
\mathrm{E}\left[u_{L}\left(\tilde{w}, r_{1}, r_{2}\right)\right]= & \phi y_{L}+\frac{1}{2} \max \left\{0,(1-\phi) y_{L}+1-\sigma-r_{1}-r_{2}\right\}+ \\
& +\frac{1}{2} \max \left\{0,(1-\phi) y_{L}+1+\sigma-r_{1}-r_{2}\right\} .
\end{aligned}
$$

Payoff of the banks. The profit that bank $b$ expects from lending to the entrepreneur if he undertakes a project of size $n \in\{S, L\}$ is:

$$
\mathrm{E}\left[r_{b}^{n}(\tilde{w})-l_{b}\right]=\frac{1}{2} r_{b}^{n}(1+\sigma)+\frac{1}{2} r_{b}^{n}(1-\sigma)-l_{b},
$$

where $r_{b}^{n}(\tilde{w})$ represents the entrepreneur's actual repayment as a function of the realization $\tilde{w}$ of his wealth. If the entrepreneur has enough wealth to repay the loan, he will repay the interest rate $r_{b}$ pledged to bank $b$; instead, in case of default his pledgeable wealth is allotted to banks according to their seniority, so that bank $b$ will get the debtor's pledgeable wealth minus the repayments owed to senior creditors, $R^{b}$, if positive. Hence, the actual repayment to bank $b$ is

$$
r_{b}^{n}\left(\tilde{w}, R^{b}\right)= \begin{cases}r_{b} & \text { if }\left(1-\phi_{n}\right) y_{n}+\tilde{w}-R^{b}>r_{b}, \\ \max \left\{\left(1-\phi_{n}\right) y_{n}+\tilde{w}-R^{b}, 0\right\} & \text { otherwise. }\end{cases}
$$

For instance, if there are only two active lenders, bank 1 and bank 2, and the repayment due to bank 1 (the senior one) is $r_{1} \leq y_{S}$, then $R^{1}=0$ and $R^{2}=r_{1}$. Hence, if the entrepreneur chooses the large project $(n=L)$, then the actual repayment to the junior bank in state $\tilde{w}$ is

$$
r_{2}^{L}\left(\tilde{w}, r_{1}\right)= \begin{cases}r_{2} & \text { if }\left(1-\phi_{L}\right) y_{L}+\tilde{w}-r_{1}>r_{2}, \\ \max \left\{\left(1-\phi_{L}\right) y_{L}+\tilde{w}-r_{1}, 0\right\} & \text { otherwise, }\end{cases}
$$


where the first line corresponds to the case of no default, and the second to default.

\section{1.b. Equilibrium}

Since with no information sharing each bank does not observe the actions previously taken by its current loan applicants, the game is one of imperfect information, so that the solution concept is Perfect Bayesian Equilibrium (PBE). We will also adopt the following tie-breaking condition: in any PBE a bank $b$ prefers to lend whenever it is indifferent between lending via an incentive compatible contract and not lending. This assumption rules out uninteresting equilibria in which banks earn profits by lending at positiveprofit rates and their competitors do not undercut them in the belief that their offers would themselves be subsequently undercut.

In characterizing the equilibrium, with no loss of generality we shall consider only equilibria where the entrepreneur borrows either $x$ or $2 x$, and signs contracts with at most two banks: by assumption (A1), if the entrepreneur were to borrow any different amount, he would have to return any credit not used for investment to the corresponding bank.

\section{Overborrowing Incentives without Information Sharing}

In our setting, multiple bank lending creates the potential for inefficiency, which arises when the entrepreneur overborrows so as to undertake the large project. Exclusive lending would rule out this outcome, since each bank could costlessly prevent the entrepreneur from borrowing from other lenders and undertake the large project. But in our model exclusivity is not enforceable: once a borrower has received a loan to fund the small project, he may borrow more and switch to the large one, so as to appropriate a fraction $\phi$ of its revenue.

For any contract $c_{1}=\left(x, r_{1}\right)$ offered by the senior bank (bank 1 hereafter), this opportunistic behavior surely occurs under two conditions. First, the junior bank has the incentive to provide additional funding, because this yields a nonnegative profit:

$$
\mathrm{E}\left[r_{2}^{L}\left(\tilde{w}, r_{1}\right)-x\right] \geq 0,
$$

where $r_{2}^{L}\left(\tilde{w}, r_{1}\right)$ is defined by expression (4). Second, the entrepreneur has the incentive to seek additional funds, because the large project yields greater expected utility than the small one:

$$
\mathrm{E}\left[u_{L}\left(\tilde{w}, r_{1}, r_{2}\right)\right]>\mathrm{E}\left[u_{S}\left(\tilde{w}, r_{1}\right)\right],
$$


where $u_{L}\left(\tilde{w}, r_{1}, r_{2}\right)$ and $u_{S}\left(\tilde{w}, r_{1}\right)$ are defined by expressions (2) and (1), and $r_{1}$ and $r_{2}$ are the repayments pledged to the senior and the junior bank, respectively.

If condition (6) were not to hold for any repayment $r_{2} \geq x$, overborrowing would never occur, because the entrepreneur would have no incentive to undertake the large project. In this case, moral hazard is no concern for lenders, who therefore can compete as under exclusivity. Conversely, when both inequalities (5) and (6) simultaneously hold for any contract $c_{1}=\left(x, r_{1}\right)$, with $r_{1} \in\left[x, y_{S}\right]$ offered by the senior bank, then overborrowing will necessarily occur. In this section, we analyze incentives to overborrow by referring to these two polar cases. Building on this preliminary analysis, in the next section we shall characterize the equilibria that arise when there is scope for overborrowing.

\subsection{EFFICIENT BENCHMARK}

Efficiency is guaranteed if, when banks require the lowest possible repayment $x$, the entrepreneur wants to undertake the small (and efficient) project - that is, inequality (6) is reversed for $r_{1}=r_{2}=x$ :

$$
\mathrm{E}\left[u_{L}\left(\tilde{w}, r_{1}=x, r_{2}=x\right)\right] \leq \mathrm{E}\left[u_{S}\left(\tilde{w}, r_{1}=x\right)\right] .
$$

Simple computations show that this efficiency condition can be rewritten as

$$
\phi y_{L} \leq v_{S}+1+\min \{0, \Delta v-\sigma\},
$$

where $\Delta v \equiv v_{S}-v_{L}$. When this inequality holds, banks can lend $x$ without fearing borrowers' opportunism, and therefore will undercut each other, pushing the equilibrium repayment down to the perfectly competitive level. Hence: ${ }^{10}$

\section{Proposition 1}

In the parameter region where

$$
\phi \leq \phi^{*}(\sigma) \equiv \frac{v_{S}+1+\min \{0, \Delta v-\sigma\}}{y_{L}},
$$

there is only a zero-profit equilibrium where the entrepreneur undertakes the small project and pledges a total repayment $x$. This region is not empty and its area is increasing in $\Delta v$ and decreasing in $\sigma$.

\footnotetext{
10 Even though for simplicity we prove the following proposition with reference to the case where each entrepreneur borrows $x$ from one bank, in this region competitive equilibrium is perfectly compatible with multiple bank lending: if an entrepreneur does not wish to take extra lending after borrowing $x$ from a single bank, he will not wish to do so either after borrowing $x / N$ from $N$ banks at the same rate.
} 
The region defined in this proposition corresponds to area $A$ in Figure 2 , where the private benefit $\phi$ from the large project is measured on the vertical axis and the volatility of collateral value $\sigma$ on the horizontal axis. Its boundary $\phi(\sigma)$ is decreasing in $\sigma$ : when the entrepreneur's wealth is riskier, overborrowing gives him a larger gain in the good state, while he is protected by limited liability in the bad state. This incentive to overborrow must be offset by a stronger creditor rights protection-that is a lower $\phi$, for a zero-profit equilibrium to exist. The magnitude of region $A$ is positively related to the excess value generated by the small project, $\Delta v$ : the greater this difference, the weaker the temptation to switch to the large project.

\subsection{OVERBORROWING}

Are there conditions on the volatility of collateral and creditor rights protection under which overborrowing necessarily emerges, that is, both inequalities (5) and (6) simultaneously hold?

First, for condition (5) to hold, it must be the case that the entrepreneur undertaking the large project defaults on both banks in the bad state. To see this, consider that if the senior bank were to recover its money in this state, it would a fortiori recover it also in the good state; since the large project is not viable, the junior bank would then make losses. Being unable to recover its money in the bad state, the junior bank must recover it entirely in the good one, where it cannot exceed the entrepreneur's pledgeable income net of the senior bank's repayment-that is $(1-\phi) y_{L}+1+\sigma-r_{1}$. This repayment is smallest when the senior bank demands the highest possible repayment $r_{1}=y_{S}$ on its loan: if even in this case the junior bank breaks even, it will always be ready to fund the entrepreneur's opportunistic borrowing. Using expression (3) with $n=L$, condition (5) then becomes

$$
\frac{1}{2}\left[(1-\phi) y_{L}+1+\sigma-y_{S}\right] \geq x .
$$

This inequality, which identifies a necessary condition for opportunistic lending to occur, provides an upper bound $\bar{\phi}(\sigma)$ on the parameter $\phi$. When the fraction $\phi$ of private benefits does not exceed this bound, the junior bank can make profits by demanding a repayment $r_{2} \geq 2 x$ (in the region defined by (9), the junior bank just breaks even if $r_{2}=2 x$ ).

It remains to be seen in which subset of this region the entrepreneur is willing to take an additional loan from the junior bank, so that also 


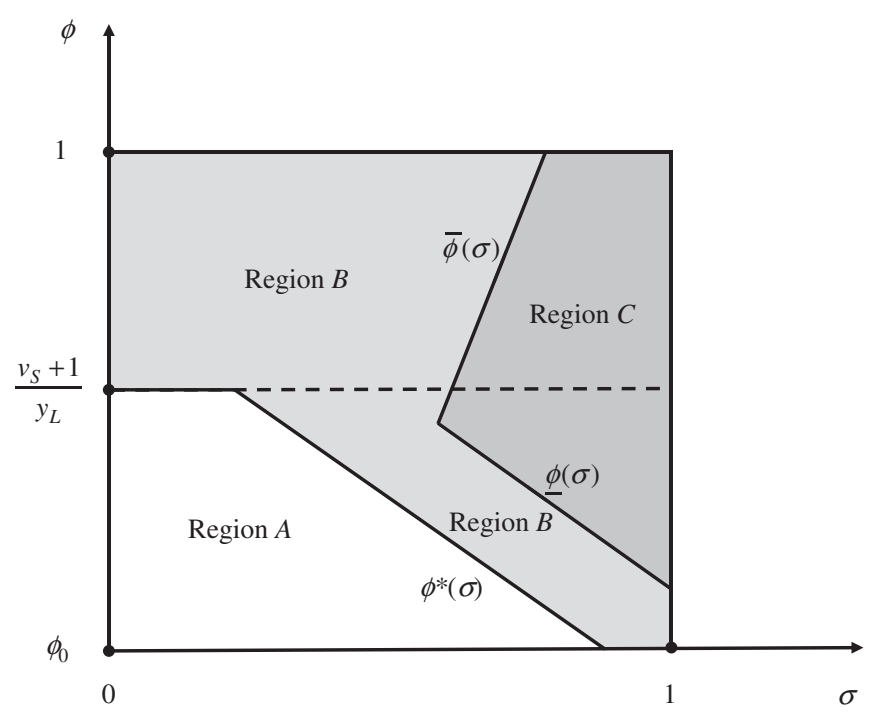

Figure 2. Parameter regions without information sharing.

condition (6) holds. Setting the junior banks's repayment at its break-even level $r_{2}=2 x$ and using expressions (2) and (1), condition (6) becomes

$$
\phi y_{L}+\frac{1}{2}\left((1-\phi) y_{L}+1+\sigma-r_{1}-2 x\right)>y_{S}-r_{1}+1 \text {. }
$$

In words, the entrepreneur wishes to undertake the large project if the implied private benefit $\left(\phi y_{L}\right)$ plus his wealth in the good state $\left((1-\phi) y_{L}+1+\sigma-r_{1}-2 x\right)$ exceed the surplus $y_{S}-r_{1}$ generated by the small project plus the expected wealth $\mathrm{E}(\tilde{w})=1$.

This condition for opportunistic borrowing is hardest to meet when the entrepreneur's utility from the small project is largest, that is, when the rate $r_{1}$ charged by the senior bank is at its lowest, $x$. Hence, imposing $r_{1}=x$ in condition (10) yields the necessary condition for the entrepreneur to undertake the large project when the junior bank is willing to fund it. This translates into a lower bound $\underline{\phi}(\sigma)$ on $\phi$ - that is, requires the large project to yield large enough private benefits.

The following proposition summarizes this discussion:

\section{Proposition 2}

In the parameter region where

$$
\phi \geq \underline{\phi}(\sigma) \equiv \phi_{0}+\frac{2 \Delta v-\sigma+x}{y_{L}}
$$


and

$$
\phi<\bar{\phi}(\sigma) \equiv \phi_{0}+\frac{\sigma-y_{S}}{y_{L}},
$$

overborrowing necessarily occurs. This region is not empty for $\Delta v+\left(y_{S}+x\right) / 2<1$.

The parameter region characterized by the above proposition is shown as region $C$ in Figure $2 .{ }^{11}$ In region $C$ moral hazard is most severe: the fraction of surplus that borrowers can steal is so large and collateral value so volatile that opportunistic lending by the junior bank may never be deterred. Interestingly, the inefficiency does not stem only from the entrepreneur's ability to extract private benefits $\phi$, but also requires a sufficiently high volatility $\sigma$ of collateral value: if the entrepreneur chooses the large project and the value of collateral is sufficiently volatile, in the good state the junior bank is able to recover the losses made in the bad state by charging a high interest rate, and this strengthens its incentive to lend. This inefficiency region vanishes when $\Delta v$ and $y_{S}$ are both very large: if the small project is very profitable $\left(y_{S}\right.$ large) or much more profitable than the large one ( $\Delta v$ large), the entrepreneur is not tempted to switch to the large project, so that moral hazard is no longer an issue.

\section{Equilibria without Information Sharing}

In the previous section, we derived the boundaries of the perfectly competitive and efficient region $A$, and of the overborrowing region $C$. As apparent from Figure 2, these boundaries also define an intermediate region $B$ : here entrepreneurs would like to overborrow, that is, condition (6) holds; yet, no junior bank would gain from providing extra funding to entrepreneurs who already borrowed $x$, that is, condition (5) is violated provided the senior bank requires a sufficiently onerous repayment from the entrepreneur, so as to make lending to him unappealing to its competitors. If instead a bank were to charge the zero-profit repayment $x$, it would not be able to deter additional lending by its competitors, that is, condition (8) is violated. This also implies that in region $B$ banks will refrain from undercutting each other down to the zero-profit repayment $x$, for fear of triggering opportunistic behavior.

$\overline{11}$ Recall that $\sigma$ ranges between 0 and 1 , and by assumption (A6) $\phi$ is between $\phi_{0}$ and 1 . 
This argument indicates that any equilibrium in this region must feature positive-profit repayments. Specifically, in this region there are two types of equilibria:

\section{Proposition 3}

In region $B$ :

(i) for every pair $(\phi, \sigma)$ there is a positive-profit equilibrium, where only one bank (say bank 1) funds the efficient project with certainty by offering the contract $c^{* *}=\left(x, r^{* *}\right)$, where $r^{* *} \in\left(x, y_{S}\right]$, and there is a subregion where the only efficient equilibrium features positive profits;

(ii) there are also zero-profit equilibria with rationing, where more than one bank is active and each offers a loan contract at a positive-profit rate with a probability less than one.

The first type of equilibrium described in this proposition is one where a single bank posts loan offers and charges a positive-profit rate, possibly so high as to extract the entire revenue from the investment, namely the monopoly rate $r^{M}=y s$. This single lender is immune from other banks' undercutting, as in Parlour and Rajan (2001). In our setting, this is because an undercutter is itself exposed to the danger of opportunistic behavior by the borrower, who could accept his offer either together with that of the incumbent or with that of another bank. Indeed, the contract $c^{* *}$ offered in this equilibrium features the largest rate among the contracts that are immune to opportunistic lending by junior banks and that cannot be profitably undercut by another contract itself immune to opportunistic lending. This equilibrium outcome is supported by an entrepreneur's strategy that always assigns seniority to the single active lender. This result is less unrealistic than it may appear: the single lender may in fact be a loan syndicate where several banks join forces to overcome their limited lending capacity due to, for instance, regulatory capital requirements.

The second type of equilibrium has the realistic feature that several banks post loan offers, unlike in Parlour and Rajan (2001). However, since each bank lends with a probability less than one, the entrepreneur may fail to obtain any loan. In this rationing equilibrium, the entrepreneur applies to all active banks, hoping to obtain loans from at least two of them, and banks accept his applications randomly, so that in equilibrium he may receive no loan, one loan or two loans. An active bank earns positive profits if the entrepreneur is granted a single loan, and makes losses if he gets two loans and defaults in the bad state. Therefore, each bank's expected profit is decreasing in the number of loans offered by competitors. The fraction of accepted loan applications is such that each bank just breaks even. ${ }^{12}$ 
Recalling that the efficient outcome requires the entrepreneur to always undertake the small project, this outcome is socially inefficient, because it entails that the entrepreneur undertakes the efficient project only with some probability, since with complementary probability he is either denied credit or enabled to undertake the large project. This rationing equilibrium differs from the sequential banking equilibrium in Bizer and DeMarzo (1992), where each borrower receives the amount of credit he desires at the equilibrium interest rate. In our setting, instead, the entrepreneur's demand for credit is rationed with positive probability at the prevailing interest rate: whereas the entrepreneur wishes to obtain a total loan of size $2 x$ at the market rate, he may end up getting only an amount $x$ or no funding at all.

The idea behind the rationing equilibrium is that no bank can profitably deviate from its loan policy by raising the probability with which it accepts loan applications, in spite of the presence of rationing: the frequency with which competitors accept applications in equilibrium is such that no bank can gain by changing its lending probability. The reason why no bank can deviate by charging a rate below the monopoly level is that it anticipates that it will not receive seniority by the entrepreneur with sufficiently high probability.

Indeed credit rationing becomes the only possible equilibrium outcome in region $C$, where moral hazard is most severe, both $\phi$ and $\sigma$ being highest: the fraction of surplus that borrowers can steal is so large and collateral value is so volatile that opportunistic lending may not be deterred, even by charging the monopoly rate. We show that in region $C$ there are equilibria with stochastic rationing (where the entrepreneur does not receive credit with certainty) as well as an equilibrium with market freeze, where no lending occurs. However, in this region the repayment structure of these rationing equilibria differs from that of region $B$ : now, three different contracts are offered in equilibrium, two of them charging "usurious repayments" $\left(r^{U}\right.$ and $\left.\underline{r}\right)$ above the monopoly level, and the other requiring the monopoly repayments. The usurious rates differ across banks: $\underline{r}$ is the lowest repayment that allows a junior bank to make zero profits when funding the large project, while $r^{U}$ is the maximum that an entrepreneurs who already borrowed at the monopolistic rate can pledge without defaulting in the good state. As shown in the Appendix, $r^{U}=(1-\phi) y_{L}+1+\sigma-y_{S}>r^{M}=y_{S}$. Summarizing:

\section{Proposition 4}

In region $C$, there are both zero-profit equilibria with rationing and an equilibrium with market freeze. In the rationing equilibrium, each bank accepts the

12 For simplicity, we analyze the case where only two banks offer contracts, but it can be shown that a continuum of rationing equilibria exists for any number of active banks. 
loan application with probability less than one. If three banks are active, one offers the monopoly contract while the others offer usurious contracts.

In the rationing equilibrium, the entrepreneur applies for both the monopoly and the usurious loans: he may get (i) no loan, (ii) a loan at the monopoly rate, (iii) both the monopoly and one of the usurious contracts, or (iv) two loans at the usurious rates. A bank issuing a monopoly loan earns profits if the entrepreneur happens to take no other loan, and makes losses if he happens to take another loan. The entrepreneur chooses the seniority structure so that both usurious banks make zero profits. In particular, a bank lending at rate $r^{U}$ makes profits if the entrepreneur signs the monopoly contract with a competitor, and losses if he does so with the other usurious lender. A bank lending at usurious rate $\underline{r}$ makes zero profits irrespective of whether the entrepreneur signs another contract at the monopoly or at the usurious rate.

The reason why there must be some banks offering loans at usurious rates is as follows. First, in this region the value of collateral is so volatile that even the monopolistic contract does not protect the bank against opportunistic lending. Second, creditor protection is so poor that a junior bank lending to an entrepreneur who already took a loan at the monopoly rate must charge more that the monopoly rate. Third, the entrepreneur is willing to borrow at such a high rate because the usurious loan allows him to appropriate part of the large project's return, while by defaulting he avoids paying this high rate in the bad state.

The probabilities with which contracts are offered in equilibrium and seniority is assigned are such that all banks make zero profits. Usurers are more likely to accept a loan application from the entrepreneur than the nonusurers and therefore are more likely to face default by the entrepreneur (as they more frequently lend together with other usurers), but charge correspondingly higher rates, in order to break even. This credit market segmentation is often observed in reality.

Note that the assumption that some banks make "secret loan offers" plays a major role in all regions: if all offers were observable, there would always be an equilibrium where only one bank is active and offers the zero-profit and efficient contract $c=(x, r=x)$. This bank would be able to protect itself against opportunistic lending by accepting applications for this contract only if no opportunistic contracts are offered by competitors.

\subsection{EMPIRICAL PREDICTIONS}

The model of multiple bank lending developed so far has two main empirical predictions: a novel one regarding the effect of the volatility of collateral 
value, and another concerning creditor rights protection which is broadly in line with the literature.

The novel testable prediction is that multibank lending entails credit rationing only if the value of collateral is sufficiently volatile: as $\sigma$ increases in Figure 2, we move from perfectly competitive equilibrium to an equilibrium with rationing and high interest and default rates. This effect does not arise in single-bank models of credit rationing, such as Holmstrom and Tirole (1997), Stiglitz-Weiss (1981), Williamson (1987) and Longhofer (1997), where increases in the volatility of collateral are neutral. The prediction is that rationing should be more widespread in countries where real estate prices are more volatile and in industries with more unstable secondary market prices for collateral. By the same token, credit rationing should be more pervasive when the instability of house prices is more pronounced, as in the recent subprime loan crisis.

Degryse, Ioannidou, and von Schedvin (2011) provide the most direct test of this prediction. Using panel data on all the commercial loans from one of the largest Swedish banks in 2002-08, they show that, when a borrower obtains a new loan from an outside bank, the initial lender tends to protect its claims by raising interest rates and/or cutting back credit, and that this negative response by the initial lender is stronger if the new loan is large and if the volatility of the borrower's collateral is high. This squares with our model's prediction that the volatility of collateral value is at the basis of the externality arising from nonexclusive lending.

The model also predicts that improving creditor protection-lowering $\phi$ in Figure 2-tends to reduce credit rationing and raise competition. If borrowers' wealth is not very volatile (low $\sigma$ ), strengthening creditor rights shifts the economy from region $B$ to region $A$, thereby improving credit access and lowering default rates. If instead in region $B$ the market features a positive-profit equilibrium, a shift to region $A$ implies more intense banking competition and lower interest rates. If borrowers' wealth is very volatile (high $\sigma$ ), better creditor protection may shift the economy from region $C$ to $B$, that is, from rationing to a positive-profit equilibrium where entrepreneurs are not rationed. In summary, the model predicts that creditor-friendly reforms increase credit availability, as in the abovementioned models of credit rationing, and reduce default and interest rates by fostering banking competition, as in Parlour and Rajan (2001).

These predictions are consistent with cross-country data and with US data on interstate differences in bankruptcy law. La Porta et al. (1997) and Djankov, McLiesh, and Shleifer (2007) show that countries with better creditor rights protection tend to feature broader credit markets. Along the same lines, Gropp, Scholz, and White (1997) find that households 
living in states with comparatively high exemptions are more likely to be turned down for credit, borrow less, and pay higher interest rates; and White (2006) shows that debt forgiveness in bankruptcy harms future borrowers by reducing credit availability and raising interest rates.

\section{Equilibria with Information Sharing}

We now turn to the regime where banks share information on entrepreneurs' borrowing histories, and in particular on their total exposure. As documented in Degryse, Ioannidou, and von Schedvin (2011), this form of information sharing, which is widespread in credit markets, helps banks to guard against the risk of default, by conditioning loan offers on the applicants' financial exposure. Information sharing has both "bright" and "dark" sides.

First, it has procompetitive effects: it expands the parameter region where perfect competition is the unique equilibrium and, even where imperfect competition persists, it lowers the equilibrium interest rate.

Relative to Figure 2, the boundaries between regions move from the dashed to the solid lines shown in Figure 3: the region where perfect competition is the only equilibrium expands from $A$ in Figure 2 to $A^{\prime}$ in Figure 3 . This expansion comes at the expense of region $B$, which shrinks to $B^{\prime}$ in Figure $3 .{ }^{13}$ In area $A^{\prime}$ positive-profit equilibria disappear, because information sharing allows outside lenders to safely undercut incumbents: starting from a positive-profit equilibrium candidate, any bank can now offer a better rate to the entrepreneur if he is not yet indebted (since it can verify his outstanding debts). Moreover, a zeroprofit equilibrium will always exist in the area between the dashed and the solid lines: if the borrower seeks to switch to the large project he can no longer obtain an additional loan at the zero-profit rate, because if a bank discovers that the borrower is already indebted, it can either refuse lending to him or equivalently require from him a break-even rate, which in this region deters him from opportunistic borrowing. As they no longer fear entrepreneurs playing them one against another, banks are now willing to offer loans of size $x$ at the zero-profit rate in equilibrium.

But even in region $B^{\prime}$ where the zero-profit contract is not an equilibrium (since such a contract would expose the senior bank to the danger of opportunistic lending ${ }^{14}$ ), the positive-profit equilibrium repayment will be lower

13 In the Appendix we show that in the special case where $\Delta v \geq 1-x$, this imperfectly competitive region disappears altogether. Hence, region $B^{\prime}$ is not empty for $\Delta v<1-x$.

14 In the Appendix we show that in area $B^{\prime}$ conditions (5) and (6) hold for $c_{1}=(x, x)$ - that is, the junior bank can profit from lending opportunistically and the entrepreneur seeks for undertaking the large project when the senior bank offers the competitive contract. 


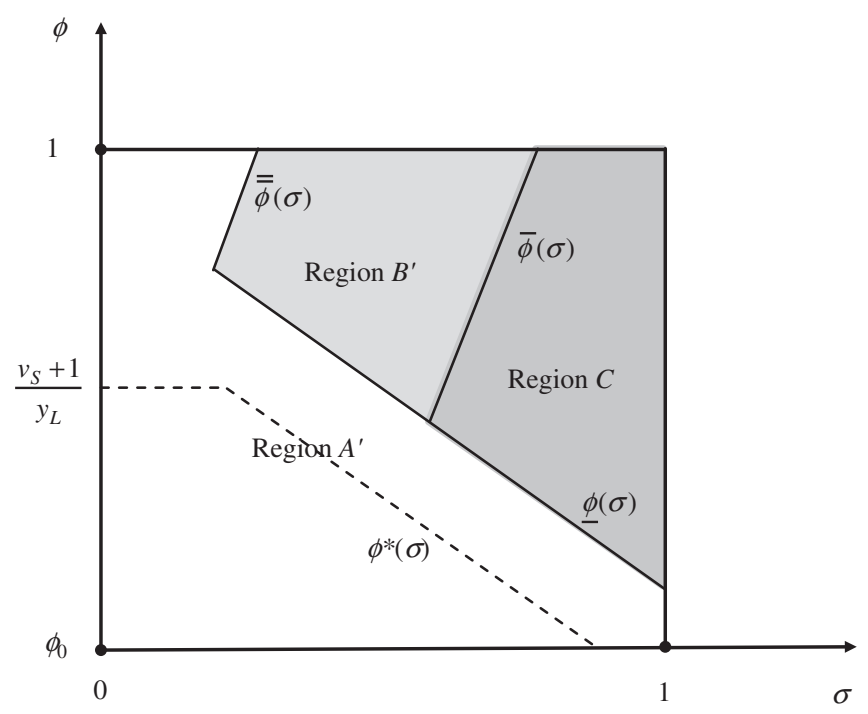

Figure 3. Parameter regions with information sharing.

than the one that would prevail without information sharing. More precisely, the unique equilibrium contract is the one that features the lowest repayment among those that are immune to opportunistic lending by junior banks and that cannot be profitably undercut by a contract itself immune to opportunistic lending.

The second "bright" side of information sharing is to eliminate rationing equilibria where the entrepreneur is funded with some probability, in regions $B$ and $C$. With information sharing, the uncertainty about how many contracts entrepreneurs have already signed vanishes. This eliminates the scope for rationing. To see why, recall that absent information sharing, in region $B$ the entrepreneur could take two loans at a rate above the zero-profit level and default. With information sharing, instead, banks can check whether the entrepreneur has not yet received credit and give him credit only in this case. In doing so, they can be confident that no competing bank will grant a second loan, anticipating that doing so would induce default and inflict losses on the junior lender.

These effects highlight the ability of information sharing to mitigate the contractual externalities that arise from the banks inability to enforce exclusivity in lending. To summarize:

\section{Proposition 5}

Under information sharing, the region with a unique, efficient and perfectly competitive equilibrium expands, and the region with positive-profit equilibrium 
shrinks correspondingly. In the latter region, the repayment is lower than the equilibrium repayment that would obtain without information sharing for the same $(\sigma, \phi)$.

However, there is also a "dark side" to information sharing: now market freeze is the only equilibrium left in region $C$. Recall that in this region, upon obtaining a loan, the entrepreneur would be willing to take additional loans at the expenses of nonusurious lenders, and usurers are willing to offer him credit, since they expect to recover their money at the expense of nonusurious lenders. In the absence of information sharing, even usurers must worry about the risk of lending to a customer already indebted with another usurer: since the large project is not viable, in this region two usurers dealing with the same client lose money. In equilibrium, this limits lending at usurious rates. With information sharing, instead, usurers can easily discover if a credit applicant is not indebted with other usurers, because his pledged repayment will be lower than it would if he had taken an usurious loan. In so doing, usurers make lending unprofitable for any bank charging lower rates, and thereby cause the loan market to freeze.

\section{Proposition 6}

In region $C$ there is a unique equilibrium with market freeze.

It may seem paradoxical that in region $C$ information sharing reduces efficiency even though it mitigates contractual externalities. The point, however, is that in this region contractual externalities between usurers were beneficial in the absence of information sharing: banks lending at usurious rates had to worry about customers playing them one against the other, which kept them from competing too aggressively against nonusurious lenders. Information sharing dispenses them from this concern, but their more aggressive lending strategy kills off the market.

\subsection{EMPIRICAL PREDICTIONS: EFFECTS OF INFORMATION SHARING}

Our results offer a number of testable predictions on how information sharing about past indebtedness should affect credit market performance. First, information sharing unambiguously reduces default and interest rates in active markets, and more so in countries with worse creditor protection and riskier collateral or, within a given country, for informationally opaque and riskier borrowers. Second, eliminating rationing should result in smaller individual loans. Third, when lenders spontaneously share information about past debts, credit availability invariably increases. If instead banks are forced to share information, credit supply will increase if the variability 
of collateral is not too large, because it will shift the economy from an equilibrium with rationing to a situation with no rationing. However, if poor creditor protection is coupled with high uncertainty on the value of borrowers' collateral, mandatory information sharing reduces credit availability, by leading to a market freeze. This "dark side" of credit reporting may be relevant in some developing countries, where potential borrowers are farmers with very risky wealth, while lenders often charge usurious rates. In such environments, information sharing would enhance the usurers' ability to target clients, and so disrupt the viability of lending at nonusurious rates.

An expanding empirical literature, based on cross-country aggregate data (Pagano and Jappelli, 1993; Jappelli and Pagano, 2002; Djankov, McLiesh, and Shleifer, 2007) and on firm-level data (Galindo and Miller, 2001; Brown, Jappelli, and Pagano, 2009), has showed that information sharing is associated with more lending and/or lower delinquencies. In particular, Doblas-Madrid and Minetti (2013), who explore contract-level data from a major US credit bureau, find that as lenders enter the bureau, they experience a decline in borrowers' delinquencies, and more so for informationally opaque and riskier clients. Moreover, access to the bureau induces creditors to grant smaller individual loans, in line with our model's prediction. A randomized experiment on a Guatemalan microfinance lender who gradually started using a credit bureau, conducted by de Janvry, McIntosh, and Sadoulet (2010), leads to broadly similar results: recourse to the credit bureau allows increased volume and efficiency of lending, with no increase in defaults.

In terms of our analysis, the expansion of lending associated with information sharing may be interpreted as an indication that in most instances information sharing reduces incentives for opportunistic lending, just as the improvement in legal protection of creditors discussed in Section 4.1. This "substitutability" relationship between information sharing and creditor protection is consistent with the evidence of Djankov, McLiesh, and Shleifer (2007) and Brown, Jappelli, and Pagano (2009).

Finally, the "dark side" of information sharing identified by our analysis may help to interpret the evidence in Herzberg, Liberti, and Paravisini (2011), that the extension of Argentina's public credit register to loans below the \$200,000 threshold in 1998 resulted in lower lending and higher default rates, for firms that borrowed from multiple lenders. This evidence accords with the effect of the introduction of information sharing in our rationing equilibrium when the uncertainty about collateral value is very high and creditor rights are poorly protected. Both of these prerequisites apply in the case at hand: Argentina scores quite low on creditor protection according to the Djankov, McLiesh, and Shleifer (2007) indicator, and the 
1998 extension in the credit register took place soon before Argentina plunged in the worst crisis of its postwar history.

\section{Robustness and Extensions}

The model used in this article is very stylized, in particular in its description of competition between banks. However, its results are robust to several changes in assumptions, provided one retains the key assumption that no bank observes all the contracts offered in the market. In particular, it is robust to the introduction of sequential offers by banks and to changes in the bargaining power of banks relative to entrepreneurs. If banks are assumed to make sequential offers as in Bizer and DeMarzo (1992), all results of the paper are unchanged, even though the proofs are more complex. In such a sequential setting, the lack of a last-stage offer plays the same role as the limited observability of banks' offers in our setting. Similarly, if bargaining power was attributed entirely to the entrepreneur as in Kahn and Mookherjee (1998), all the zero-profit equilibrium outcomes (with or without rationing) would still exist, and so would the positive-profit equilibria that arise in the absence of information sharing. The reason is that in all these equilibria, the interest rate is driven by competition down to the minimal level that allows banks to earn nonnegative profits, so that under no circumstances a change in bargaining power can lead banks to lend at lower rates. The only difference with respect to our results is that, in the absence of information sharing, any positive-profit equilibrium with a single active bank no longer exists, because the entrepreneur could always profitably deviate by making a take-it-or-leave-it offer of a cheaper contract to such a bank.

In the rest of this section, we discuss two further extensions of the model: the case where banks may voluntarily share information about their clients' indebtedness, and a regime where the information sharing system allows them to constantly monitor their clients' exposure even after the loan contract has been signed. The first extension is aimed at investigating whether in our setting the private and the social incentives to share information are aligned; the second makes the simple point that in the extreme, information sharing can achieve the same outcome as exclusive lending.

\subsection{SPONTANEOUS INFORMATION SHARING}

In several countries, publicly managed credit registries consolidate information on borrowers' credit worthiness, which typically includes their total 
indebtedness. But there are also many countries where private information sharing systems (credit bureaus) have been developed by financial intermediaries on a voluntary basis, as a response to information asymmetries (Miller, 2003). This naturally raises the issue of why banks may want to share information on entrepreneurs' indebtedness, and whether their incentives to do so are aligned with social efficiency. Our multiple bank lending setup can be used to make a step toward investigating this issue. ${ }^{15}$

To this purpose, we consider an "expanded" version of the game considered so far, which also includes an initial stage $(t=-1)$ where each bank announces whether it wishes to share information about its borrowers' promised repayment. For brevity, we focus on the case where these announcements are simultaneous and binding, and keep the analysis at an informal level.

As in the rest of the article, the information-sharing arrangement is assumed to be costless: this rules out the possibility that banks may fail to set up a mutually advantageous credit reporting system only because they cannot agree on how to share its costs. We also neglect trivial equilibria where each bank does not share information only because it believes that its competitors will also refrain from doing so. Abstracting from such wellknown coordination failures allows us to investigate whether there may be other sources of inefficiency in the decision to create an information sharing arrangement, which are inherently related to the externalities between lenders and borrowers analyzed so far.

Finally, banks are assumed to opt for information sharing only if there is at least an equilibrium of the game in which this choice is strictly profitable for them. This refinement is meant to capture the idea that banks do not share worthless information just because it is free. In what follows, the equilibrium outcomes of our expanded game are analyzed separately for the three areas of Figure 2.

Regions $A$ and $C$ are the easiest to analyze. Since in region $A$ opportunistic behavior by borrowers and lenders can be deterred at no cost, banks cannot gain from sharing information. Hence, information is not shared. The same conclusion holds in region $C$, but for a different reason: here information sharing would increase the scope for opportunistic lending. More specifically, in this region a bank that discloses information about its clients' indebtedness cannot obtain a positive profit, whichever repayment it requires. This is for the

\footnotetext{
15 A similar issue is studied by Leitner (2012) in the context of a market for credit default swaps. He explores protection buyers' incentives to report trades with a protection seller who can trade with multiple counterparties, and describes a simple central mechanism that induces buyers to truthfully report trades, and thereby achieve efficiency.
} 
same reasons by which in this region information sharing (if exogenously imposed) leads to market freeze by Proposition 6. First, a bank that reveals to competitors that it has required a repayment below (or equal to) the monopoly rate simply attracts opportunistic lending by them, and thus incurs losses. But even banks offering rates above the monopoly level do not benefit from revealing it, because this would simply deter other banks from offering rates below the monopoly level, hence preventing profitable lending.

Things become more interesting, but also more complex, in region $B$. Here, disclosure of a client's indebtedness could increase the lender's profits, since it prevents opportunistic borrowing and thus reduces the borrower's default probability. Are these potential benefits sufficient to align private and social incentives for information sharing? The answer to this question is negative in general: in region $B$, there are both efficient equilibria where banks choose to share information and inefficient equilibria where they do not, even though they could do so.

More specifically, whether voluntary information sharing emerges in region $B$ depends on how the entrepreneur chooses his contractual partner when several banks offer the same rate and therefore is indifferent between them. The intuition for this multiplicity of equilibria is best seen by considering two specific cases: (i) that where the entrepreneur is "loyal" to a specific bank (possibly because of switching costs), namely, always chooses to borrow from it unless some other bank offers a cheaper loan, and (ii) the case where the entrepreneur is "unloyal" and has a weak preference for banks sharing information, that is chooses randomly among the best-priced offers made by banks sharing information, provided these offers are not worse than those of banks that do not disclose information.

\section{1.a Loyal entrepreneurs}

Banks choose not to share information if the entrepreneur is "loyal". In this case, the credit market features both of the two equilibria outcomes presented in Section 4, that is the positive-profit equilibrium with a single active bank and the rationing equilibrium. In both types of equilibria, active banks charge the maximal rate $r^{* *}$ that is not vulnerable either to opportunistic lending or to undercutting.

To see why no bank has the incentive to share information in each of these two equilibria, consider first the equilibrium where only bank 1 is active and the entrepreneur is loyal to this bank. This bank will not want to share information, because it correctly anticipates that upon disclosing it, its contract $\left(x, r^{* *}\right)$ becomes prone to safe undercutting by any competitor. Moreover, no other bank wishes to share information, if bank 1 chooses 
not to do so: each anticipates that sharing information with banks other than bank 1 is useless, given that the entrepreneur is loyal to bank 1 .

Consider next the equilibrium with rationing, which entails zero profits for all banks. In this equilibrium, bank 1 may want to share information: the reason is that, if information is shared, the rationing equilibrium disappears and the only equilibrium outcome is one where the small project is funded at the lowest repayment rate that is robust to safe undercutting. If this rate exceeds the zeroprofit one, bank 1 will be able to capture this profit because of the entrepreneur's loyalty. However, bank 1's competitors will not want to share information, as they anticipate that customer's loyalty will prevent them from getting any profit. Hence, also in this equilibrium information will not be shared.

\section{1.b Unloyal entrepreneurs}

Recall that in this case the entrepreneur chooses randomly among the offers with the cheapest rate made by banks sharing information, unless some bank that does not share information offers an even lower rate. If banks earn positive profits by offering the contract $\left(x, r^{*}\right)$ that charges the minimal rate not vulnerable to undercutting or to opportunistic lending, there are only equilibria where the banks posting offers share information and lend $x$ at the rate $r^{*}$. The intuition for this result is as follows. The weak preference displayed by the entrepreneur for banks sharing information ensures that each of the banks that choose to share information and offer the contract $\left(x, r^{*}\right)$ gets the profit associated to this contract with equal probability: no bank is willing to lend at a rate below $r^{*}$, as it would be vulnerable to opportunistic lending or to undercutting. Hence these banks will earn positive expected profits if they share information, and accordingly they will choose to share information.

In summary, if borrowers are "loyal", in area $B$ banks will refrain from sharing information about their indebtedness even when it would be socially efficient to do so; conversely, banks will efficiently share information if entrepreneurs are "unloyal" and weakly prefer lenders who share information. The main policy implication is that competitive behavior does not necessarily lead banks to engage in socially beneficial information sharing, which creates some scope for policy interventions aimed at mandating information sharing systems.

\subsection{FULL INFORMATION SHARING AND LOAN COVENANTS}

So far, our analysis has proceeded under the simplifying assumption that, in the information sharing regime, banks can only use retrospective 
information on their credit applicants' indebtedness. Alternatively, one could envisage a situation in which banks use a credit register to check exposures even after lending, and therefore condition their contracts to the subsequent borrowing undertaken by their clients. This regime, that we label "full information sharing", is equivalent to a situation where exclusive contracts are enforceable, provided banks can impose loan covenants that force early liquidation and repayment if total indebtedness exceeds a specified threshold before the investment is made.

Hence, when banks can write and costlessly enforce loan covenants, full information sharing leads to a unique efficient and perfectly competitive equilibrium for all parameter values, so that its beneficial effects are magnified. However, in reality covenants are costly to write and enforce; moreover, lenders may become aware of their violation after the investment stage. In these cases, full information sharing becomes effectively equivalent to the regime where only retrospective information is shared, as assumed in Section 5 .

\section{Concluding Remarks}

When people can borrow from several banks, lending by each bank increases the customer's default risk. We show that the strength of this contractual externality depends on the variability of collateral value and on creditor rights protection. When creditor rights are well protected, the externality is absent or tenuous, so that banks can lend at zero-profit rates without fearing that their customers will take additional loans. When creditor protection is in an intermediate range, this externality generates equilibria with positive-profit rates and possibly credit rationing of some applicants. When the value of collateral is sufficiently volatile, the equilibrium always involves rationing and even usurious rates by some lenders.

For moderate levels of creditor protection and collateral volatility, information sharing mitigates these contractual externalities by allowing banks to condition their loans on the borrower's contractual history, so to guard themselves against opportunistic lending by competitors. As a result, it increases access to credit by eliminating rationing. However, in situations where collateral values are very uncertain and creditor rights are poorly protected, information sharing exacerbates credit rationing and induces market freeze: this may be relevant for some developing countries or more generally at times of great turbulence, like financial crises.

Our model has three main testable predictions. First, credit rationing should be tighter, and interest and default rates larger when collateral is risky and creditor rights are poorly protected. Second, information sharing 
about past debts should reduce default and interest rates. Third, information sharing should increase credit access when the value of collateral is relatively stable, but reduce it when collateral is very risky. These three predictions are consistent with the empirical evidence.

\section{Appendix: Proofs}

For simplicity, throughout the proofs we assume that there are only four banks. The loan offers issued by banks 1 and 2 are common knowledge, whereas banks 3 and 4 are hidden lenders, that is, their loan offers are not observable by competitors. Moreover, we characterize credit market equilibria where any active bank offers only loans of size $x$. This restriction is inconsequential, because for any $\mathrm{PBE}$ where the entrepreneur borrows $l \notin\{0, x\}$ there is another equilibrium where $l \in\{0, x\}$ and is payoff-equivalent for the entrepreneur. For instance, a competitive equilibrium where two banks lend $x / 2$ each is payoff-equivalent to one in which a single bank lends $x$ at competitive terms. This is because the entrepreneur has no incentive to borrow a total sum that differs from $x$ or $2 x$, not being able to steal extra funding not needed to carry out one of the two projects. Hence, he will find it optimal to borrow at most $2 x$, even if he may apply to many banks. However, no bank will want to lend $2 x$, since it knows that this allows the entrepreneur to undertake the financially unviable project. We denote the zero-profit contract by $c^{P C}=(x, x)$ and the monopoly contract by $c^{M}=\left(x, y_{S}\right)$, where $x$ and $y_{S}$ are the respective required repayments. Moreover, $\underline{c}=(x, 2 x)$ denotes the contract that allows a junior bank to earn zero profits if the entrepreneur defaults on all banks in the bad state and does not default in the good state, assuming $\phi \leq \bar{\phi}(\sigma)$ (recall from Section 3.2 that under this condition the junior bank just breaks even when it requires the repayment $2 x$ ). Finally, it is convenient to define by $c_{\emptyset}=(0,0)$ the "null contract", that is a situation in which a bank is inactive.

To save on notation, in these proofs $\pi^{S}\left(r_{b} \mid r_{b^{\prime}}\right)$ denotes bank $b$ 's expected profit when the entrepreneur accepts contract $c_{b}=\left(x, r_{b}\right)$ from bank $b$ together with contract $c_{b^{\prime}}=\left(x, r_{b^{\prime}}\right)$ from bank $b^{\prime}$, gives seniority to bank $b$, and undertakes the large project; $\pi^{J}\left(r_{b} \mid r_{b^{\prime}}\right)$ is the corresponding expression when bank $b$ is junior. Similarly, $\pi\left(r_{b}\right)$ will denote bank $b$ 's expected profit when the entrepreneur signs only $c_{b}=\left(x, r_{b}\right)$ and undertakes the small project.

Strategies under no information sharing. Each player's strategy depends on the observable past history of the game. Since banks 1 and 2 can observe each other's contracts but not those issued by the hidden lenders, each of them can condition the acceptance of a loan offer only on the contract 
offered by the other. In contrast, hidden banks 3 and 4 can condition the acceptance of a loan offer on the vector $\mathbf{c}=\left(c_{1}, c_{2}\right)$ of contracts issued by banks 1 and 2 .

Hence, under no information sharing, for any $b \in\{1,2\}$, bank $b$ 's strategy $\left\{c_{b}, \alpha_{b}(\mathbf{c})\right\}$ specifies an offer $c_{b}$ and an acceptance rule $\alpha_{b}(\mathbf{c})$ which maps bank $b$ 's information into an acceptance decision for $c_{b}$. In contrast, for any $b \in\{3,4\}$, bank $b$ 's strategy $\left\{c_{b}, \alpha_{b}\left(c_{b}, \mathbf{c}\right)\right\}$ specifies an offer $c_{b}$ and an acceptance rule $\alpha_{b}\left(c_{b}, \mathbf{c}\right)$ that maps bank $b$ 's information into an acceptance decision for $c_{b}$.

Let $\tilde{\alpha} \in\{0,1\}^{4}$ be the vector indicating the banks' acceptance decisions of the entrepreneur's applications, where in the $b$-th entry 0 stands for rejection and 1 for acceptance of $c_{b}$. Moreover, denote by $\mathrm{C}=\left(c_{b}\right)_{b=1}^{4}$ the vector of contracts issued by the four banks. For any pair $(\mathrm{C}, \tilde{\alpha})$, the entrepreneur's strategy $\rho(\mathbf{C}, \tilde{\alpha})$ specifies the set of contracts signed and the seniority assigned to the financiers.

In order to simplify the description of the entrepreneur's strategy, in all the proofs characterizing equilibria with no information sharing, we restrict (without loss of generality) the entrepreneur's strategy space by imposing the individual rationality property $S^{E}$ stated below, which also includes tie-breaking rules to specify his choice when indifferent between contracts. To define this property, we denote $C^{E}$ as the set of contracts whose application has been accepted by some bank and $\tilde{\mathrm{C}}^{\mathrm{E}}$ as the set of all possible pairs of contracts in $C^{E} \cup c_{\emptyset} \cup c_{\emptyset}$. Then the entrepreneur's strategy has property $S^{E}$ if he behaves as follows:

(i) since loan applications are costless, at stage 2 the entrepreneur applies to all banks. At stage 3, he signs only one contract $c_{b} \in \mathrm{C}^{E}$ if $r_{b} \leq r^{M}, r_{b} \leq r_{b^{\prime}} \forall b^{\prime} \neq b, r_{b}<r_{b^{\prime \prime}} \forall b^{\prime \prime}<b$, and he prefers the small project to the large one:

$$
\mathrm{E}\left[u_{S}\left(\tilde{w}, r_{b}\right)\right] \geq \mathrm{E}\left[u_{L}\left(\tilde{w}, r_{b}, r_{b^{\prime}}\right)\right], \quad \forall c_{b^{\prime}}=\left(x, r_{b^{\prime}}\right) \in \mathrm{C}^{\mathrm{E}} ;
$$

(ii) he signs no contract if $r_{b}>r^{M} \forall c_{b} \in \mathrm{C}^{E}$ and he prefers to consume his endowment to investing in the large project:

$$
\mathrm{E}[\tilde{w}]=1 \geq \mathrm{E}\left[u_{L}\left(\tilde{w}, r_{b}, r_{b^{\prime}}\right)\right], \quad \forall\left(c_{b}, c_{b^{\prime}}\right) \in \tilde{\mathrm{C}}^{\mathrm{E}} ;
$$

(iii) he undertakes the large project and signs the two contracts $\left(c_{b}, c_{b^{\prime}}\right) \in \mathrm{C}^{\mathrm{E}}$ if they offer lower rates than any other available pair of contracts:

$$
\mathrm{E}\left[u_{L}\left(\tilde{w}, r_{b}, r_{b^{\prime}}\right)\right] \geq \mathrm{E}\left[u_{L}(\tilde{w}, \mathbf{r})\right], \quad \forall \mathbf{r}=\left(r_{b^{\prime \prime}}, r_{b^{\prime \prime}}\right),
$$

with $\left(c_{b^{\prime \prime}}, c_{b^{\prime \prime \prime}}\right) \in \tilde{\mathrm{C}}^{E}$ and $r_{b^{\prime \prime}}>\max \left\{r_{b}, r_{b^{\prime}}\right\}$ if $b^{\prime \prime}<\min \left\{b, b^{\prime}\right\}$; 
(iv) finally, the entrepreneur chooses the small project whenever he is indifferent between signing one contract and undertaking the small project or signing two contracts and undertaking the large one.

As for the banks, again for simplicity, we impose without loss of generality that their strategies imply no sure loss, that is, that they only offer contracts with rate at least as large as $x$. We shall refer to this property of banks' strategies as property $S^{B}$.

Proof of Proposition 1. We first prove existence and then uniqueness.

Existence. Consider the candidate equilibrium where $(i)$ all banks issue the contract $c^{P C}=(x, x)$, (ii) each bank accepts the application for this contract with probability 1 regardless of the contracts issued by its competitors, and (iii) out of equilibrium, does not accept applications for other contracts. The entrepreneur applies to all active banks and assigns seniority with equal probability to any of the banks offering his preferred contract.

Players' beliefs about the issuance and acceptance of secret offers are such that each bank sticks to its equilibrium strategy also out of equilibrium, thus satisfying the condition that players "do not signal what they do not know", defined by Fudenberg and Tirole (1991, p. 332). Banks' beliefs about competitors' acceptances are as follows: banks that at $t=2$ observe the vector $\mathbf{c}=\left(c_{1}, c_{2}\right)$ of publicly observable offers believe that a bank issuing a publicly observable contract, which has deviated from its equilibrium strategy, will accept the entrepreneur's application with the probability prescribed by its equilibrium strategy.

The strategies and out-of-equilibrium beliefs described above identify a PBE. Indeed, given the banks' strategy, the entrepreneur's strategy maximizes his expected utility since the following inequality is satisfied for $\phi \leq \phi(\sigma)$ :

$$
\mathrm{E}\left[u_{S}(\tilde{w}, x)\right]=v_{S}+1 \geq \mathrm{E}\left[u_{L}(\tilde{w}, x, x)\right]=\phi y_{L}+\mathrm{E}\left[\max \left\{(1-\phi) y_{L}+\tilde{w}-2 x\right\}\right] .
$$

Moreover, banks cannot profitably deviate, since no contract $c^{\prime}=\left(x^{\prime}, r^{\prime}\right) \neq c^{P C}$ earns positive profits. Indeed, condition (A1) guarantees that the entrepreneur will not sign a contract $c^{\prime}=\left(x^{\prime}, r^{\prime}\right)$ with $r^{\prime}>x$. Showing that banks' strategies are sequentially rational is straightforward, since in the region under consideration $c^{P C}=(x, x)$ is not vulnerable to opportunistic lending and condition (A1) holds.

Finally, beliefs about the probabilities of out-of-equilibrium acceptances by banks making observable offers satisfy the PBE consistency requirement 
because these probabilities are "pinned down" by equilibrium strategies: all players believe that any bank deviating at stage $t=1$ will follow its equilibrium strategy at stage $t=3$, and this behavior is optimal given the competitors' equilibrium strategy.

Uniqueness. We must show that for $\phi \leq \phi(\sigma)$ there is no equilibrium where a contract $c=(x, r)$, with $r>x$, is signed by the entrepreneur. The condition $\phi \leq \phi(\sigma)$, together with the continuity of the entrepreneur's expected utility, implies that $\mathrm{E}\left[u_{S}\left(\tilde{w}, r^{\prime}\right)\right] \geq \mathrm{E}\left[u_{L}\left(\tilde{w}, r^{\prime}, r\right)\right]$, with $r^{\prime}$ sufficiently close to $x$ and $r^{\prime}<r$, that is, that the entrepreneur will not want to undertake the large project if he can take a loan at the rate $r^{\prime}$. As a consequence, assumption $\mathbf{A 6}$ guarantees that if $c^{P C}$ is not offered, any bank can profitably deviate by offering a rate close enough to $x$. Indeed, this contract makes positive profits if accepted by the entrepreneur. Therefore, a necessary condition for the entrepreneur to sign contracts charging noncompetitive rates in equilibrium is that all banks earn positive profits. But then by assumption A6 some bank will undercut its competitors. Hence, this cannot be an equilibrium.

Finally, region $A$ is nonempty since $\phi(\sigma)>0$ at $\sigma=1$, so that $\phi(\sigma)>0$ for all $\sigma$.

Proof of Proposition 2. We will show that $\phi \leq \bar{\phi}(\sigma)$ and $\phi>\phi(\sigma)$ are necessary and sufficient conditions for an efficient equilibrium not to exist. That is, in this area there is no contract $c_{1}=\left(r_{1}, x\right)$, with $r_{1} \in\left[x, y_{S}\right]$, offered by the senior bank (say, bank 1 for concreteness) that deters entry by the junior bank (say, bank 2) when the entrepreneur wishes to borrow opportunistically and undertake the large project. To this purpose, we will show that, for any contract $c_{1}$ offered by bank 1 , in this parameter region there always exists a contract $c_{2}$ such that the following conditions hold simultaneously:

- the entrepreneur defaults on bank 1 in the bad state when he undertakes the large project:

$$
(1-\phi) y_{L}+1-\sigma-r_{1}<0, \quad \forall r_{1} \in\left[x, y_{S}\right]
$$

- there is no default in the good state when the entrepreneur undertakes the large project:

$$
(1-\phi)+1+\sigma-r_{1}-r_{2}>0, \quad \forall r_{1} \in\left[x, y_{S}\right]
$$

- the junior bank's expected profit from funding the large project is nonnegative:

$$
\pi^{J}\left(c_{2} \mid c_{1}\right) \geq 0, \quad \forall r_{1} \in\left[x, y_{S}\right]
$$


- the entrepreneur's expected utility from the large project exceeds that from the small project:

$$
\mathrm{E}\left[u_{L}\left(\tilde{w}, r_{1}, r_{2}\right)\right]>\mathrm{E}\left[u_{S}\left(\tilde{w}, r_{1}\right)\right] .
$$

Condition (A2) is necessary for an efficient equilibrium not to exist: if the senior bank is fully repaid in all states, then the junior bank makes losses by lending opportunistically because the large project is not viable, that is, condition (A4) does not hold. Condition (A3) is also necessary for an efficient equilibrium not to exist: if the junior bank is not able to recover its money in the good state, then condition (A4) cannot hold.

In what follows, we first show that $\phi \leq \bar{\phi}(\sigma)$ and $\phi>\phi(\sigma)$ are sufficient conditions for (A2), (A3), (A4), and (A5) to hold, and then prove that they are also necessary.

Sufficiency. We first assume (and verify ex post) that (A2) and (A3) are satisfied in region $C$. Hence, consider equation (A4). The junior bank's expected profit from lending to the entrepreneur undertaking the large project is

$$
\pi^{J}\left(c_{2} \mid c_{1}\right)=\frac{1}{2} \max \left\{r_{2},(1-\phi) y_{L}+1+\sigma-r_{1}\right\}-x .
$$

Note that if $\pi^{J}\left(c_{2} \mid c_{1}\right)>0$ at $r_{1}=y_{S}$, there is no contract $c_{1}$ that the senior bank can offer which prevents the junior bank 2 from lending opportunistically to the entrepreneur. It can then be easily verified that $\phi \leq \bar{\phi}(\sigma)$ directly implies $\pi^{J}\left(c_{2} \mid c^{M}\right)>0$, so that $\pi^{J}\left(c_{2} \mid c_{1}\right) \geq 0$ for each $r_{2} \geq 2 x$ and $r_{1} \in\left[x, y_{S}\right]$.

Next, consider condition (A5). If conditions (A2), (A3), and (A5) are met, the entrepreneur's expected utility from opportunistic borrowing is

$$
\mathrm{E}\left[u_{L}\left(\tilde{w}, r_{1}, r_{2}\right)\right]=\phi y_{L}+\frac{1}{2}\left((1-\phi) y_{L}+1+\sigma-r_{1}-r_{2}\right),
$$

while his utility from the small project is

$$
\mathrm{E}\left[u_{S}\left(\tilde{w}, r_{1}\right)\right]=y_{S}+1-r_{1} .
$$

Note that the difference $\mathrm{E}\left[u_{S}\left(\tilde{w}, r_{1}\right)\right]-\mathrm{E}\left[u_{L}\left(\tilde{w}, r_{1}, r_{2}\right)\right]$ is decreasing in $r_{1}$. Hence, the best rate that the senior bank can charge to discourage further opportunistic lending is $r_{1}=x$. If the junior bank just breaks even, then the entrepreneur prefers to borrow opportunistically and implement the large project if

$$
\phi y_{L}+\frac{1}{2}\left((1-\phi) y_{L}+1+\sigma-3 x\right)>y_{S}+1-x .
$$


It is easy to verify that $\phi>\phi(\sigma)$ directly implies condition (A7). Hence, $\phi \leq \bar{\phi}(\sigma)$ and $\phi>\phi(\sigma)$ are sufficient conditions for an efficient equilibrium not to exist.

To conclude the proof of sufficiency, we show that conditions (A2) and (A3) are satisfied in region $C$. Solving for $\phi$ in condition (A2) when $r_{1}=x$, we have:

$$
\phi \geq \frac{v_{L}+1-\sigma+x}{y_{L}} .
$$

It is immediate that the above inequality is directly implied by $\phi>\underline{\phi}(\sigma)$ because:

$$
\underline{\phi}(\sigma)=\frac{v_{L}+2 \Delta v+1-\sigma+x}{y_{L}}>\frac{v_{L}+1-\sigma+x}{y_{L}} .
$$

Inequality (A3) is, instead, directly implied by condition (A6).

Necessity. We now show that $\phi>\phi(\sigma)$ and $\phi \leq \bar{\phi}(\sigma)$ are also necessary conditions for an efficient equilibrium not to exist. Suppose first that $\phi>\bar{\phi}(\sigma)$. By construction, in this area the senior bank can charge a rate $r_{1}$ that is sufficiently high to inflict losses on the junior bank when it allows the borrower to undertake the large project. Hence, $\phi \leq \bar{\phi}(\sigma)$ is also necessary for an efficient equilibrium not to exist. Suppose now that $\phi \leq \bar{\phi}(\sigma)$ and $\phi<\phi(\sigma)$. By continuity of the entrepreneur's expected utility, in this area there is a repayment $r_{1} \geq x$ such that $E\left[u_{L}\left(\tilde{w}, r_{1}, 2 x\right)\right] \leq \mathrm{E}\left[u_{S}\left(\tilde{w}, r_{1}\right)\right]$, so that opportunistic borrowing is not profitable for the entrepreneur. Hence, $\phi>\phi(\sigma)$ and $\phi \leq \bar{\phi}(\sigma)$ are also necessary conditions for an efficient equilibrium not to exist.

Finally, to conclude the proof of Proposition 2, note that $\phi(\sigma)=\bar{\phi}(\sigma)$ for $\sigma=\left(y_{S}+x\right) / 2+\Delta v$. Hence, recalling that $\sigma \in[0,1]$, region $C$ is not empty if $\left(y_{S}+x\right) / 2+\Delta v<1$. It is also useful to notice that $\left(y_{S}+x\right) / 2+\Delta v<1$, together with the assumption that the large project is financially unviable, directly implies $2 x>y_{S}$, so that $\underline{r} \equiv 2 x>r^{M}$ in region $C$.

The next lemma and the subsequent corollary, which are instrumental to characterize market equilibria in region $B$, show that in this region there is a set $K$ of contracts that are not vulnerable to opportunistic lending and cannot be profitably undercut. This set $K$ is made of the contracts $c=(x, r)$ for which the following inequalities hold:

$$
\begin{gathered}
\mathrm{E}\left[u_{L}\left(\tilde{w}, r, r^{\prime}\right)\right] \leq \mathrm{E}\left[u_{S}(\tilde{w}, r)\right] \text { or } \pi^{J}\left(c^{\prime} \mid c\right) \leq 0, \quad \forall c^{\prime}=\left(x, r^{\prime}\right) \text { with } r^{\prime}>r, \\
\mathrm{E}\left[u_{L}\left(\tilde{w}, r, r^{\prime \prime}\right)\right] \geq \mathrm{E}\left[u_{S}\left(\tilde{w}, r^{\prime \prime}\right)\right], \quad \forall c^{\prime \prime}=\left(x, r^{\prime \prime}\right) \text { with } r^{\prime \prime} \geq x \text { and } r^{\prime \prime}<r .
\end{gathered}
$$


Denote by $c^{*}=\left(x, r^{*}\right)$ the contract with lowest rate in $K$ and by $c^{* *}=\left(x, r^{* *}\right)$ the contract whose rate $r^{* *}$ is the minimum between $y_{S}$ and the maximal rate in $K$.

Lemma 1. In region $B$ the set $K$ is non-empty and $r^{*}<y_{S}$.

Proof. Consider separately the case $2 x<y_{S}$ and the case $2 x>y_{S}$ :

Case 1. $2 x<y_{S}$. Assume that $\mathrm{E}\left[u_{L}(\tilde{w}, x, \underline{r})\right]<\mathrm{E}\left[u_{S}(\tilde{w}, x)\right]$. This inequality implies that $c^{P C}$ satisfies the condition (A8) strictly. We now show that there is a repayment $r=x+\varepsilon$, with $\varepsilon$ positive and small enough such that any contract $c=(x, r)$ with $r \in(x, x+\varepsilon)$ satisfies conditions (A8) and (A9). By continuity any contract with a rate in the interval $(x, x+\varepsilon)$ satisfies (A8). In addition, in the interior of region $B$ we also have

$$
\mathrm{E}\left[u_{L}(\tilde{w}, x, x)\right]>\mathrm{E}\left[u_{S}(\tilde{w}, x)\right],
$$

and the continuity of the entrepreneur's expected utility implies:

$$
\mathrm{E}\left[u_{L}(\tilde{w}, x, x+\varepsilon)\right]>\mathrm{E}\left[u_{S}(\tilde{w}, x)\right],
$$

for $\varepsilon$ small enough. Hence, any $c=(x, r)$, with $r \in(x, x+\varepsilon)$, also satisfies (A9) for $\varepsilon$ small enough.

Alternatively, assume that $\mathrm{E}\left[u_{L}(\tilde{w}, x, \underline{r})\right] \geq \mathrm{E}\left[u_{S}(\tilde{w}, x)\right]$. We will show that for any sufficiently small $\delta \leq 0$ the contract $c_{\delta}=(x, 2 x+\delta)$ satisfies conditions (A8) and (A9). To this end, assume that the entrepreneur undertakes the large project and signs $c_{\delta}$ with his senior lender. Consider first the subcase where $(1-\phi) y_{L}+1+\sigma>2 x$, that is, the entrepreneur's pledgeable wealth in the good state exceeds than the rate charged by the senior lender. Then the entrepreneur repays $2 x+\delta$ to the senior lender in the good state. And since the good state occurs with probability $1 / 2$, the senior lender makes positive profits, as he also receives $\tilde{r}=\min \left\{2 x+\delta,(1-\phi) y_{L}+1-\sigma\right\}>0$ in the bad state. Hence, no junior contract taken together with $c_{\delta}$ can be profitable for $|\delta|$ small enough, since the large project is financially unviable, implying that $c_{\delta}=(x, 2 x+\delta)$ meets condition (A8).

Consider now the alternative subcase where $(1-\phi) y_{L}+1+\sigma \leq 2 x$. Then the entrepreneur who signs $c_{\delta}$ with his senior lender will default in both states for $|\delta|$ small enough, so that the senior lender appropriates all his pledgeable wealth. As a consequence, a junior bank that allows the entrepreneur to fund the large project will make losses. Hence, also in this case $c_{\delta}$ satisfies condition (A8) for $|\delta|$ small enough. Moreover, since $\mathrm{E}\left[u_{L}(\tilde{w}, x, \underline{r})\right] \geq \mathrm{E}\left[u_{S}(\tilde{w}, x)\right]$, the contract $c_{\delta}$ also satisfies condition (A9) for 
$|\delta|$ small enough. This is because, as one can readily verify, the difference $\mathrm{E}\left[u_{L}\left(\tilde{w}, r, r^{\prime \prime}\right)\right]-\mathrm{E}\left[u_{S}\left(\tilde{w}, r^{\prime \prime}\right)\right]$ is increasing in $r^{\prime \prime}$.

Case 2. $2 x \geq y_{S}$. Again, assume first that $\mathrm{E}\left[u_{L}(\tilde{w}, x, \underline{r})\right]<\mathrm{E}\left[u_{S}(\tilde{w}, x)\right]$. The continuity of the entrepreneur's expected utility implies that $c=(x, x+\varepsilon)$ satisfies condition (A8) for $\varepsilon$ small enough. Moreover in region $B$, by definition, any $c=(x, x+\varepsilon)$, with $\varepsilon$ positive and small enough, satisfies (A9).

Consider now the case where $\mathrm{E}\left[u_{L}(\tilde{w}, x, r)\right] \geq \mathrm{E}\left[u_{S}(\tilde{w}, x)\right]$. In this case, the inequality $\mathrm{E}\left[u_{L}(\tilde{w}, x, r)\right]>\mathrm{E}\left[u_{S}(\tilde{w}, x)\right]$ holds for all $r<2 x$, hence for all $r \in\left[x, y_{S}\right]$, since $\mathrm{E}\left[u_{L}(\tilde{w}, x, r)\right]$ is monotone in $r$. Thus, (A9) is satisfied by any contract $c=(x, r)$ with $r \in\left[x, r^{M}=y_{S}\right]$. Moreover, by Proposition 2, for any point in the interior of region $B$, there exists a nonempty set $\left[r^{*}, r^{* *}\right]$ such that any contract with a rate in this interval satisfies (A8). Therefore, all contracts with rates in $\left(r^{*}, r^{* *}\right)$ satisfy conditions (A8) and (A9).

Corollary 1. For any $c=(x, r)$ and $c^{\prime}=\left(x, r^{\prime}\right)$ with $r<r^{\prime}<r^{* *}$, the following inequality holds:

$$
\mathrm{E}\left[u_{L}\left(\tilde{w}, r, r^{\prime}\right)\right] \geq \mathrm{E}\left[u_{S}(\tilde{w}, r)\right] .
$$

Proof. For $r^{\prime} \geq r^{*}$ the inequality directly follows from the previous lemma and the definition of the set $K$, upon replacing $r^{\prime \prime}=r^{\prime}$ in condition (A9). For $r^{\prime}<r^{*}$, the inequality $\mathrm{E}\left[u_{L}\left(\tilde{w}, r, r^{\prime}\right)\right] \geq \mathrm{E}\left[u_{S}(\tilde{w}, r)\right]$ is implied by the fact that $\mathrm{E}\left[u_{L}\left(\tilde{w}, r, r^{\prime}\right)\right]-\mathrm{E}\left[u_{L}(\tilde{w}, r)\right]$ is decreasing in $r^{\prime}$.

Proof of Proposition 3. We prove the proposition by splitting it in two parts, (i) and (ii).

Part ( $i)$. In region $B$, there is a PBE where only one bank is active and offers the positive profit contract $c^{* *}=\left(x, r^{* *}\right)$, with $r^{* *}>x$.

Proof. Let $L(c)$ be the (possibly empty) set of loan contracts that a bank can profitably sign with the entrepreneur, if the latter has already signed $c$ with a senior lender. Formally:

$$
L(c) \equiv\left\{c^{\prime}: \pi^{J}\left(c^{\prime} \mid c\right)>0 \text { and } \mathrm{E}\left[u_{L}\left(\tilde{w}, r, r^{\prime}\right)\right]>\mathrm{E}\left[u_{S}\left(\tilde{w}, r^{\prime}\right)\right]\right\} .
$$

We will show that the positive-profit equilibrium is supported by the following strategies.

Banks' strategies. At the initial stage $t=1$, banks 1 and 2 issue $c^{* *}$ and all other banks remain inactive. At $t=3$, banks making public offers 
adopt the following acceptance policy. For $r_{1}=r_{2},\left(\alpha_{1}, \alpha_{2}\right)=(1,0)$, for $r_{1} \neq r_{2}, b^{\prime} \in\{1,2\}$ and $b^{\prime \prime} \in\{1,2\}$ with $b^{\prime} \neq b^{\prime \prime}$ :

$$
\left(\alpha_{b^{\prime}}, \alpha_{b^{\prime \prime}}\right)=(1,0) \text { if } r_{b^{\prime}} \in\left[x, y_{S}\right] \text { and } c_{b^{\prime \prime}}=c_{\emptyset} \text { or } \mathbf{c}=\left(c_{b^{\prime}}, c_{b^{\prime \prime}}\right) \in \mathbf{C},
$$

where

$$
\begin{array}{r}
\mathbf{C} \equiv\left\{\mathbf{c}: r_{b^{\prime}} \leq r^{* *}, r_{b^{\prime \prime}} \leq r^{* *} \text { and } \mathrm{r}_{b^{\prime \prime}} \leq \mathrm{r}_{b^{\prime}} ; \mathrm{r}_{b^{\prime}} \leq r^{* *}, r_{b^{\prime \prime}}>r^{* *} \text { and } c_{b^{\prime \prime}} \notin L\left(c_{b^{\prime}}\right) ;\right. \\
\left.r_{b^{\prime}}>r^{* *}, r_{b^{\prime \prime}}<r^{* *} \text { and } c_{b^{\prime}} \in L\left(c_{b^{\prime \prime}}\right) ; r_{b^{\prime}}>r^{* *} ; r_{b^{\prime \prime}} \geq r^{* *} \text { and } r_{b^{\prime}}>r_{b^{\prime \prime}}\right\} \\
\left(\alpha_{b^{\prime}}, \alpha_{b^{\prime \prime}}\right)=(0,1) \text { if } c_{b^{\prime}}=c_{\emptyset} \text { and } r_{b^{\prime \prime}} \in\left[x, y_{S}\right] \text { or } \mathbf{c}=\left(c_{b^{\prime}}, c_{b^{\prime \prime}}\right) \notin \mathbf{C} ;
\end{array}
$$

Moreover, bank $\hat{b}$, with $\hat{b}=\{3,4\}$, chooses $\alpha_{\hat{b}}=1$ if $\left(\mathbf{c}, c_{\hat{b}}\right)$ satisfies either one of the following two conditions:

c is such that $\alpha_{b}(\mathbf{c})=0$ for $b=1,2$ and $r_{\hat{b}} \in\left[x, y_{S}\right]$ or

c is such that $\alpha_{b}(\mathbf{c})=1$ with $b \in\{1,2\}, c_{\hat{b}} \in L\left(c_{b}\right)$ or $\mathrm{E}\left[u_{S}\left(\tilde{w}, r_{\hat{b}}\right)\right] \geq \mathrm{E}\left[u_{L}(\tilde{w}\right.$, $\left.\left.r_{\hat{b}}, r_{b}\right)\right]$ and $\pi\left(c_{\hat{b}}\right) \geq 0$; and chooses $\alpha_{b}=0$ otherwise.

Entrepreneur's strategy. The entrepreneur's strategy satisfies the individual rationality property $S^{E}$ defined above. Moreover, whenever the entrepreneur signs two contracts, $c_{b}$ and $c_{b^{\prime}}$, he assigns seniority as follows:

- if $r_{b} \leq r^{* *}$ and $r_{b^{\prime}} \leq r^{* *}$ or $r_{b}>r^{* *}$ and $r_{b^{\prime}}>r^{* *}$ and both $b$ and $b^{\prime}$ are either banks making observable offers or hidden lenders, seniority is assigned to each of them with probability $1 / 2$;

- if $r_{b} \leq r^{* *}, r_{b^{\prime}}>r^{* *}$ and both $b$ and $b^{\prime}$ are either banks making observable offers or hidden lenders, seniority is assigned to bank $b$;

- if the offer of bank $b$ is publicly observable and that of bank $b^{\prime}$ is not, seniority is assigned to bank $b$.

Beliefs. Players' beliefs about the issuance and the acceptance of secret offers satisfy the usual condition that deviating players "do not signal what they do not know", so that each bank believes that hidden lenders are inactive both on and off the equilibrium path. Banks' beliefs on competitors' acceptance behavior are as follows: banks observing at $t=2$ the vector $\mathbf{c}$ of publicly observable offers believe that a lender offering a publicly observable contract, who has deviated from his equilibrium strategy, accepts the entrepreneur's application with probability $\alpha_{b}(\mathbf{c})$ - that is, with the probability prescribed by its equilibrium strategy.

If all players behave according to their equilibrium strategy, the entrepreneur ends up signing $c^{M}$ with the only active bank. Moreover, it is straightforward to check that property $S^{E}$ guarantees that the entrepreneur 
cannot profitably deviate at any stage, since his utility is the same regardless of the assignment of seniority across banks. In addition, if any of the banks deviates from its equilibrium strategy at $t=1$, then its acceptance policy at $t=3$ prescribes not to accept an application. As a consequence, if all banks follow their equilibrium strategy at $t=3$, none of them can profitably deviate at $t=1$.

In the following, we prove that the strategies described above are sequentially rational at stage $t=3$ and that out-of-equilibrium beliefs are consistent with equilibrium strategies.

Step 1. The strategies of bank 1 and bank 2 are sequentially rational.

Since banks' common out-of-equilibrium beliefs are that each lender follows its equilibrium strategy, bank $b$, with $b \in\{1,2\}$, believes that bank $\hat{b}$, with $\hat{b} \in\{3,4\}$, remains inactive. Moreover, $\alpha_{b^{\prime \prime}}(\mathbf{c})=0$ for $\mathbf{c} \in \mathbf{C}$; hence, if $\mathbf{c} \in \mathbf{C}$ or $c_{b^{\prime \prime}}=c_{\emptyset}$ bank $b^{\prime}$ believes that all competitors are inactive, which makes $\alpha_{b^{\prime}}=1$ sequentially rational for $\mathbf{c} \in \mathbf{C}$ and for $c_{b^{\prime \prime}}=c_{\emptyset}$ and $c_{b^{\prime}}$.

Assume now that $r_{b^{\prime}} \leq r^{* *}$ and $c \notin \mathbf{C}$. Then, by construction, $\alpha_{b^{\prime \prime}}=1$ and either $r_{b^{\prime}}<r_{b^{\prime \prime}}<r^{* *}$ or $r_{b^{\prime \prime}}>r^{* *}$, and $c_{b^{\prime \prime}} \in L\left(c_{b^{\prime}}\right)$. In the former case, by Corollary 1 the entrepreneur signs both $c_{b^{\prime \prime}}$ and $c_{b^{\prime}}$ if his applications for these two contracts are accepted. In the latter case, the same holds true, according to the definition of $L\left(c_{b^{\prime}}\right)$. Moreover, for $r_{b^{\prime}}<r_{b^{\prime \prime}}<r^{* *}$, the entrepreneur's strategy prescribes to assign seniority to bank $b^{\prime}$ and bank $b^{\prime \prime}$ with probability $1 / 2$ when he signs both $c_{b^{\prime}}$ and $c_{b^{\prime \prime}}$. Hence, the fact that the large project is financially unviable, together with $r_{b^{\prime}}<r_{b^{\prime \prime}}$ and $\alpha_{b^{\prime \prime}}=1$, implies that bank $b^{\prime}$ makes negative profits whenever it accepts the entrepreneur's application for $c_{b^{\prime}}$. Similarly, by the definition of $L\left(c_{b^{\prime}}\right)$, bank $b^{\prime}$ makes negative profits if $r_{b^{\prime \prime}}>r^{* *}$, and $c_{b^{\prime \prime}} \in L\left(c_{b^{\prime}}\right)$. Thus, $\alpha_{b^{\prime}}=0$ is sequentially rational.

Finally, consider the situation in which $r_{b^{\prime}}>r^{* *}$, and $\mathbf{c} \notin \mathbf{C}$. Hence, either $r_{b^{\prime \prime}} \geq r^{* *}$ and $r_{b^{\prime \prime}}>r_{b^{\prime}}$ or $c_{b^{\prime}} \notin L\left(c_{b^{\prime \prime}}\right)$. In the former case, the entrepreneur's strategy prescribes to assign seniority to each of the two banks with probability $1 / 2$ whenever both $c_{b^{\prime}}$ and $c_{b^{\prime \prime}}$ are signed; in the latter, instead, it prescribes to always assign seniority to bank $b^{\prime \prime}$. As a consequence, bank $b^{\prime}$ makes negative profits if it accepts the entrepreneur's application, and $\alpha_{b^{\prime}}=0$ is again sequentially rational.

Step 2. The strategies of bank 3 and bank 4 are sequentially rational.

Bank $\hat{b} \in\{3,4\}$ believes that its competitor issuing secret contracts remains inactive and that, out of equilibrium, banks 1 and 2 play according to equilibrium strategies, which implies $\left(\alpha_{b^{\prime}}, \alpha_{b^{\prime \prime}}\right) \in\{(1,0),(0,1)\}$ for all 
possible $\mathbf{c} \neq\left(c_{\emptyset}, c_{\emptyset}\right)$. Therefore, as banks issuing secret contracts are always junior when the entrepreneur signs two contracts, $\alpha_{\tilde{b}}=1$ is rational at $t=3$ only if either $(i) \mathbf{c}=\left(c_{\varnothing}, c_{\varnothing}\right)$ and $r_{\tilde{b}} \in\left[x, y_{S}\right]$ or $(i i) \mathbf{c}$ implies $\alpha_{b}(\mathbf{c})=1$, and $c_{\tilde{b}} \in L\left(c_{b}\right)$ or $(i i i) u\left(c_{\tilde{b}}, c_{\emptyset}\right) \geq u\left(c_{\tilde{b}}, c_{b}\right)$ and $\pi\left(c_{\tilde{b}}\right) \geq 0$.

Step 3. Beliefs are consistent with equilibrium strategies.

Out-of-equilibrium beliefs about the acceptance probabilities by banks making observable offers satisfy the PBE consistency requirements because these probabilities are "pinned down" by equilibrium strategies: all players believe that any bank deviating in $t=1$ follows its equilibrium strategy in $t=3$ and the latter is the optimal response to the competitors' equilibrium strategy.

Part (ii). In region $B$, there is an equilibrium with rationing where only banks 1 and 2 are active, issue the contract $c^{* *}$ - that is, the contract with the highest rates among those not vulnerable both to banks' undercutting and opportunistic lending - and accept applications with probability $\alpha^{* *}<1$. This rationing equilibrium is supported by the following strategies. At $t=1$, banks 1 and 2 issue $c^{* *}$ and the other banks are inactive.

At $t=3$, if $\mathbf{c}=\left(\mathbf{c}_{b^{\prime}}=c^{* *}, \mathbf{c}_{b^{\prime \prime}}=c^{* *}\right)$ bank $b \in\{1,2\}$ accepts applications for $c_{b}=c^{* *}$ with probability $\alpha^{* *}$ solving:

$$
(1-\alpha) \pi\left(c^{* *}\right)+\frac{\alpha}{2}\left[\pi^{S}\left(c^{* *} \mid c^{* *}\right)+\pi^{J}\left(c^{* *} \mid c^{* *}\right)\right]=0,
$$

where $\alpha^{* *} \in(0,1)$ as $\pi\left(c^{* *}\right)>0$, and $\pi^{S}\left(c^{* *} \mid c^{* *}\right)+\pi^{J}\left(c^{* *} \mid c^{* *}\right)<0$ since the large project is financially unviable, implying that the total surplus shared by the two banks funding this project is negative.

For any $\mathbf{c} \neq\left(c_{b^{\prime}}=c^{* *}, c_{b^{\prime \prime}}=c^{* *}\right)$, the acceptance policy of bank $b$ is the same as that in the positive-profit equilibrium in Part $(i)$.

Moreover if $\mathbf{c}=\left(c_{b^{\prime}}=c^{* *}, c_{b^{\prime \prime}}=c^{* *}\right)$, each bank $\hat{b} \in\{3,4\}$ remains inactive at $t=3$, or adopts the same acceptance policy as in Part $(i)$. Finally, out-ofequilibrium beliefs are also the same as those in the positive-profit equilibrium in Part ( $i$ ).

Under these strategies, the entrepreneur cannot profitably deviate if $\mathbf{c}=\left(c_{b^{\prime}}=c^{* *}, c_{b^{\prime \prime}}=c^{* *}\right)$, since he signs all contracts whose applications are accepted and

$$
\mathrm{E}\left[u_{L}\left(\tilde{w}, r^{* *}, r^{* *}\right)\right]>\mathrm{E}\left[u_{S}\left(\tilde{w}, r^{* *}\right)\right]>\mathrm{E}[\tilde{w}]=1 .
$$

Similarly, no bank can profitably deviate at $t=3$ if $\mathbf{c}=\left(c_{b^{\prime}}=c^{* *}, c_{b^{\prime \prime}}=\right.$ $\left.c^{* *}\right)$. Indeed, each bank $b \in\{1,2\}$ obtains zero expected profit for any 
$\alpha_{b} \in[0,1]$ if bank $b^{\prime}$ chooses $\alpha_{b^{\prime}}=\alpha^{* *}$. In addition, for bank $\hat{b} \in\{3,4\}$ it is optimal not to accept any application at $t=3$ if $\mathbf{c}=\left(c_{b^{\prime}}=c^{* *}, c_{b^{\prime \prime}}=c^{* *}\right)$. This is because $c^{* *}$ cannot be profitably undercut and the entrepreneur assigns seniority to bank $b$ whenever he signs $c_{\hat{b}}$ jointly with $c^{* *}$. As a consequence, the contract $c_{\hat{b}}$, if signed by the entrepreneur, makes the expected profit:

$$
\left(1-\alpha^{* *}\right)^{2} \pi\left(c_{\hat{b}}\right)+2 \alpha^{* *}\left(1-\alpha^{* *}\right)\left[\pi^{S}\left(c_{\hat{b}} \mid c^{* *}\right)+\pi^{J}\left(c_{b} \mid c^{* *}\right)\right] .
$$

It is straightforward to verify that the value of this expression is strictly lower than the expected profit that bank 1 and bank 2 earn when bank $b$ remains inactive, namely:

$$
\left(1-\alpha^{* *}\right) \pi\left(c^{* *}\right)+\frac{\alpha^{* *}}{2}\left[\pi^{S}\left(c^{* *} \mid c^{* *}\right)+\pi^{J}\left(c^{* *} \mid c^{* *}\right)\right],
$$

which is equal to zero by construction.

Moreover, by the same argument as in part (i) neither the entrepreneur nor any bank can profitably deviate at $t=3$ if $\mathbf{c} \neq\left(c_{b^{\prime}}=c^{* *}, c_{b^{\prime \prime}}=c^{* *}\right)$, implying that banks' equilibrium strategies are sequentially rational, and players' out-of-equilibrium beliefs are rational at this stage. Finally, it is straightforward to verify that no bank can profitably deviate at $t=1$ if all acceptance policies at $t=3$ are sequentially rational.

Proof of Proposition 4. We prove the proposition by splitting it into two parts, $(i)$ and (ii).

Part (i). In region $C$, there is an equilibrium with rationing where three banks are active and two of them charge usury rates.

Let $c^{U}=\left(x, r^{U}\right)$ with $r^{U}=(1-\phi) y_{L}+1+\sigma-y_{S}$ be the contract that extracts all of the entrepreneur's pledgeable income in the good state when signed jointly with $c^{M}$. Note that the fact that $c^{M}$ is vulnerable to opportunistic lending in region $C$ implies $r^{U}>\underline{r}=2 x>r^{M}=y_{S}$.

Before establishing existence, we prove the following result. Assume that banks 1, 2, and 3 issue the triple of contracts $\left(c_{1}=c_{M}, c_{2}=\underline{c}, c_{3}=c_{U}\right)$, bank 4 remains inactive, and the entrepreneur applies for all contracts and chooses the following strategy: (i) he signs $c^{M}$ but neither $\underline{c}$ nor $c^{U}$ if only one bank accepts his application; (ii) he always signs the two contracts with the lowest rates whenever at least two applications are accepted; (iii) he assigns seniority to the issuer of contract $c^{M}$ whenever his application for this contract is accepted, and assigns seniority to $\underline{c}$ with probability $\beta \in(0,1)$ whenever signing both $\underline{c}$ and $c^{U}$. 
Then, there is a vector $\left(\alpha_{1}=\alpha_{M}^{*}, \alpha_{2}=\alpha_{Z}^{*}, \alpha_{3}=\alpha_{U}^{*}\right) \in(0,1)^{3}$ and a number $\beta^{*} \in(0,1)$ such that all banks earn zero expected profit and bank 2 also earns zero expected profit whenever it funds the large project together with bank 3:

$$
\beta^{*} \pi^{S}\left(\underline{c} \mid c^{U}\right)+\left(1-\beta^{*}\right) \pi^{J}\left(\underline{c} \mid c^{U}\right)=0 .
$$

To prove this result, note first that in region $C$ there is a $\beta^{*} \in(0,1)$ solving (A11) since $\pi^{J}\left(\underline{c} \mid c^{U}\right)<0$ and:

$$
\begin{aligned}
\pi^{S}\left(\underline{c} \mid c^{U}\right)= & \frac{1}{2} \min \left\{2 x,(1-\phi) y_{L}+1-\sigma\right\} \\
& +\frac{1}{2} \min \left\{2 x,(1-\phi) y_{L}+1+\sigma\right\}-x>0 .
\end{aligned}
$$

Moreover, if the entrepreneur behaves according to properties (i)-(iii) above, the zero-profit conditions for banks 1, 2, and 3 are respectively:

$$
\begin{gathered}
\left(1-\alpha_{Z}^{*}\right)\left(1-\alpha_{U}^{*}\right) \pi\left(c^{M}\right)+\alpha_{Z}^{*} \pi^{S}\left(c^{M} \mid \underline{c}\right)+\alpha_{U}^{*}\left(1-\alpha_{Z}^{*}\right) \pi^{S}\left(c^{M} \mid c^{U}\right)=0, \\
\alpha_{M}^{*} \pi^{J}\left(\underline{c} \mid c^{M}\right)+\left(1-\alpha_{M}^{*}\right) \alpha_{U}^{*}\left[\beta^{*} \pi^{S}\left(\underline{c} \mid c^{U}\right)+\left(1-\beta^{*}\right) \pi^{J}\left(\underline{c} \mid c^{U}\right)\right]=0, \\
\alpha_{M}^{*}\left(1-\alpha_{Z}^{*}\right) \pi^{J}\left(c^{U} \mid c^{M}\right)+\left(1-\alpha_{M}^{*}\right) \alpha_{Z}^{*}\left[\left(1-\beta^{*}\right) \pi^{S}\left(c^{U} \mid \underline{c}\right)+\beta^{*} \pi^{J}\left(c^{U} \mid \underline{c}\right)\right]=0 .
\end{gathered}
$$

Then (A11) implies that (A13) holds because $\pi^{J}\left(\underline{c} \mid c^{M}\right)=0$ in region $C$ by the definition of $\underline{c}$. The system of equations (A12)-(A14) can then be rewritten as:

$$
\begin{aligned}
& \left(1-\alpha_{Z}^{*}\right)\left(1-\alpha_{U}^{*}\right) \pi\left(c^{M}\right)+\alpha_{Z}^{*} \pi^{S}\left(c^{M} \mid \underline{c}\right)+\alpha_{U}^{*}\left(1-\alpha_{Z}^{*}\right) \pi^{S}\left(c^{M} \mid c^{U}\right)=0, \\
& \alpha_{M}^{*}\left(1-\alpha_{2}^{*}\right) \pi^{J}\left(c^{U} \mid c^{M}\right)+\left(1-\alpha_{M}^{*}\right) \alpha_{Z}^{*}\left[\left(1-\beta^{*}\right) \pi^{S}\left(c^{U} \mid \underline{c}\right)+\beta^{*} \pi^{J}\left(c^{U} \mid \underline{c}\right)\right]=0,
\end{aligned}
$$

where $\left(1-\beta^{*}\right) \pi^{S}\left(c^{U} \mid \underline{c}\right)+\beta^{*} \pi^{J}\left(c^{U} \mid \underline{c}\right)<0$ because the large project is not viable and $\pi^{S}\left(c^{M} \mid c^{U}\right) \leq \pi^{S}\left(c^{M} \mid \underline{c}\right)<0$ since in region $C$ the monopoly contract $c^{M}$ is vulnerable to opportunistic lending. It is then immediate to verify that for any $\alpha_{Z}^{*}$ small enough, (A15) has a unique solution $\left(\alpha_{M}^{*}, \alpha_{U}^{*}\right) \in(0,1)^{2}$.

In what follows, we prove that there is a zero-profit equilibrium where banks 1,2 , and 3 issue the contract $c^{M}$, $\underline{c}$, and $c^{U}$ and accept applications with probabilities $\alpha_{M}^{*}, \alpha_{Z}^{*}$, and $\alpha_{U}^{*}$, respectively. This equilibrium is supported by the following strategies and beliefs. 
Banks' strategies. At $t=1$, bank 1 issues $c^{M}$, bank 2 issues $\underline{c}$, bank 3 issues $c^{U}$ and bank 4 remains inactive. At $t=3$, bank $b$, for $b \in\{1,2\}$ adopts the following acceptance policy:

$$
\left(\alpha_{b^{\prime}}(\mathbf{c}), \alpha_{b^{\prime \prime}}(\mathbf{c})\right)= \begin{cases}\left(\alpha_{M}^{*}, \alpha_{Z}^{*}\right) & \text { if }\left(c_{b^{\prime}}=c^{M}, c_{b^{\prime \prime}}=\underline{c}\right), \\ (1,0) & \text { if }\left(c_{b^{\prime}}=\underline{c}, c_{b^{\prime \prime}} \neq c^{M}\right) \text { or if }\left(c_{b}=\underline{c}, c_{b^{\prime}}=\underline{c}\right) \\ \alpha_{b}=\alpha_{b^{\prime}}=0 & \text { otherwith } b<b^{\prime},\end{cases}
$$

Instead, bank 3's acceptance policy is:

$$
\alpha_{3}\left(\mathbf{c}, c_{3}\right)= \begin{cases}1 \quad & \text { if } \alpha_{b}(\mathbf{c})=0 \text { for } b=1,2, \text { and } r_{3} \leq r^{M} \\ & =y^{S} \text { or } c_{b} \neq \underline{c} \text { for } \mathrm{b}=1,2 \\ \alpha_{U}^{*} & \text { if }\left(c_{b^{\prime}}, c_{b}\right)=\left(c^{M}, c^{U}\right) \\ 0 & \text { otherwise }\end{cases}
$$

Entrepreneur's strategy. The entrepreneur's strategy satisfies property $S^{E}$. Moreover, whenever the entrepreneur signs two contracts, $c_{b}$ and $c_{b^{\prime}}$, he assigns the seniority as follows:

- if $r_{b} \leq r^{M}$ and $r_{b^{\prime}}>r^{M}$, seniority is assigned to bank $b$;

- if $r_{b} \in\left(r_{M}, r\right]$ and $r_{b^{\prime}}>\underline{r}$, seniority is assigned to bank $b$ with probability $\beta^{*}$ such that:

$$
\beta^{*} \pi^{S}\left(c_{b} \mid c_{b^{\prime}}\right)+\left(1-\beta^{*}\right) \pi^{J}\left(c_{b} \mid c_{b^{\prime}}\right)=0 ;
$$

- in all other cases, the entrepreneur assigns the seniority with probability equal to $1 / 2$ to each lender.

Beliefs. Bank $b$, for $b \in\{1,2,3\}$, and the entrepreneur believe that bank 4 remains inactive in all stages.

All banks and the entrepreneur believe that any deviating lender issuing a publicly observable contract, as well as bank 3 , accept the entrepreneur's application with a probability equal to $\alpha_{b}(\mathbf{c})$ for $b \in\{1,2,3\}$, that is, with the probability prescribed by its equilibrium strategy.

If all banks and the entrepreneur play the strategies just described, the entrepreneur ends up signing $c^{M}$ with the only active bank. Moreover, as in Proposition 3, property $S^{E}$ guarantees that the entrepreneur cannot profitably deviate at any stage, and (A12), (A13) and (A14) imply that all banks make zero profits. Finally, it is immediate to verify that if any bank, say bank $b$, deviates from its equilibrium strategy at $t=1$, but all banks, including bank $b$, behave according to the acceptance policy described above in stage $t=3$, then bank $b$ makes zero profits. As a consequence, in order to 
prove that the strategies and beliefs described above support a PBE we need to show that at stage $t=3$ they are sequentially rational and that out-ofequilibrium beliefs are consistent with equilibrium strategies.

\section{Step 1. The strategies of bank 1 and bank 2 are sequentially rational.}

First, if $\mathbf{c}=\left(c_{b^{\prime}}=c^{M}, c_{b^{\prime \prime}}=\underline{c}\right)$, bank $b^{\prime}$ and bank $b^{\prime \prime}$ make zero profits for any $\alpha_{b^{\prime}} \in[0,1]$ and $\alpha_{b^{\prime \prime}} \in[0,1]$, given the equilibrium strategy of the entrepreneur and those of the hidden lenders. Hence $\alpha_{b^{\prime}}=\alpha_{M}^{*}$ and $\alpha_{b^{\prime \prime}}=\alpha_{U}^{*}$ are sequentially rational.

Second, if $\left(c_{b^{\prime}}=\underline{c}, c_{b^{\prime \prime}} \neq c^{M}\right)$ or $\left(c_{b}=\underline{c}, c_{b^{\prime}}=\underline{c}\right)$ with $b<b^{\prime}$, then bank $b^{\prime}$ earns zero expected profit for any $\alpha_{b^{\prime}} \in(0,1)$, since according to equilibrium acceptance policies (and common out-of-equilibrium beliefs) it is the only bank active in the market, and in region $C$ the inequality $2 x>y_{S}$ holds, so that the entrepreneur does not apply for $\underline{c}$ if it is the only contract issued in the market. Moreover, given the entrepreneur's seniority assignment, bank $b^{\prime \prime}$ makes negative profits for any possible $\alpha_{b^{\prime \prime}} \in(0,1]$. In particular, $\pi^{S}\left(c_{b^{\prime \prime}} \mid \mathcal{c}\right)<0$ if $r_{b^{\prime \prime}} \leq r_{M}$, as in region $C$ any contract with a rate lower than $r^{M}$ is vulnerable to opportunistic lending. In addition, the expected profit of bank $b^{\prime \prime}$ is also negative either if $r^{M} \leq r_{b^{\prime \prime}} \leq \underline{r}$, because in this case the entrepreneur assigns seniority to bank $b^{\prime \prime}$ with probability $1 / 2$ whenever he signs $c_{b^{\prime}}$ and $c_{b^{\prime \prime}}$, and $\pi^{S}\left(c_{b^{\prime \prime}} \mid \underline{c}\right)+\pi^{J}\left(c_{b^{\prime \prime}} \mid \underline{c}\right)<0$ as the large project is unviable, or if $r_{b^{\prime \prime}}>\underline{r}$, because in this case the entrepreneur assigns seniority to bank $b^{\prime \prime}$ with probability $1-\beta^{*}$ and (A11), together with the unviability of the large project, implies $\left(1-\beta^{*}\right) \pi^{S}\left(c_{b^{\prime \prime}} \mid \underline{c}\right)+\beta^{*} \pi^{J}\left(c_{b^{\prime \prime}} \mid \underline{c}\right)<0$.

Third, if $\left(c_{b^{\prime}} \neq c_{M}, c_{b^{\prime \prime}} \neq \underline{c}\right)$, then bank 3 according to its equilibrium strategy (and the competitors' out-of-equilibrium beliefs) accepts the entrepreneur's application for $c^{U}$ with probability 1 ; then for bank $b$, with $b \in\{1,2\}$ it is rational to choose $\alpha_{b}=0$ for any possible $c_{b}$, given the entrepreneur's equilibrium strategy. This is because, if bank $b$ has issued $c_{b}$ with $r_{b} \leq r^{M}$ and chooses $\alpha_{b} \in(0,1]$, it gets $\pi^{S}\left(c_{b} \mid c_{U}\right)<0$. If instead bank $b$ issues $c_{b}$ with $r^{M} \leq r_{b} \leq \underline{r}$, it obtains zero profits:

$$
\beta^{*} \pi^{S}\left(c_{b} \mid c^{U}\right)+\left(1-\beta^{*}\right) \pi^{J}\left(c_{b} \mid c^{U}\right)<\beta^{*} \pi^{S}\left(\underline{c} \mid c^{U}\right)+\left(1-\beta^{*}\right) \pi^{J}\left(\underline{c} \mid c^{U}\right)=0 .
$$

Finally, if bank $b$ has issued $c_{b}$ with $r_{b} \geq \underline{r}$, it obtains the expected profit $(1 / 2)\left[\pi^{S}\left(c_{b} \mid c^{U}\right)+\pi^{J}\left(c_{b} \mid c^{U}\right)\right]$, which is negative since the large project is financially unviable.

Step 2. The strategies of bank 3 and 4 are sequentially rational.

If $\mathbf{c}=\left(c_{b^{\prime}}=c^{M}, c_{b^{\prime \prime}}=\underline{c}\right)$ and $c_{3}=c^{U}$, then choosing probabilities $\alpha_{3}\left(\mathbf{c}, c_{3}\right)=\alpha_{U}^{*}$ if $c_{3}=c_{\emptyset}$ and $\alpha_{3}\left(\mathbf{c}, c_{3}\right)=0$ otherwise, is sequentially rational at $t=3$. This is because if $c_{3}=c^{U}$ the expected profits of bank 3 are zero, 
according to the entrepreneur's and the banks' equilibrium strategies for any $\alpha_{3} \in[0,1]$; if instead $c_{3} \neq c^{U}$ bank 3's expected profits are nonpositive for any $\alpha_{3} \in[0,1]$. Similarly, bank 3's acceptance policy prescribing $\alpha_{3}=1$ is sequentially rational if $\alpha_{b^{\prime}}(\mathbf{c})=\alpha_{b^{\prime}}(\mathbf{c})=\mathbf{0}$, since for $r_{3} \leq r^{M}$ bank 3 , given its beliefs, maximizes its profit by choosing $\alpha_{3}=1$, while earning zero profits for any possible $\alpha_{3}$ if $r_{3}>r^{M}$ (as the entrepreneur will not sign a contract with such a rate). Moreover, for bank 3 it is rational to choose $\alpha_{3}=0$ for any possible $c_{3}$ either if the pair of contracts issued by banks 1 and 2 is $\left(c_{b^{\prime}}=\underline{c}, c_{b^{\prime \prime}} \neq c^{M}\right)$ or if it is $\left(c_{b}=\underline{c}, c_{b^{\prime}}=\underline{c}\right)$. Indeed in both cases bank $b^{\prime}$ accepts the entrepreneur's application with probability 1 so that bank 3's expected profit is $\pi^{S}\left(c_{3} \mid \underline{c}\right)<0$ for $r_{3} \leq r^{M}$, and is equal to $\beta \pi^{S}\left(c_{3} \mid \underline{c}\right)+(1-\beta) \pi^{J}\left(c_{3} \mid \underline{c}\right)$, with $\beta \leq 1 / 2$ for $r_{3}>r^{M}$, which is again negative because the large project is financially unviable.

Finally, consider bank 4. For this bank it is sequentially rational to stay inactive for any possible c. Indeed, if the other banks play their equilibrium strategies, it is easy to verify that for any $c_{4}$, with $r_{4} \in\left[x, r^{U}\right]$, bank 4 obtains a profit lower than bank 3's equilibrium profit, namely

$$
\alpha_{M}^{*}\left(1-\alpha_{Z}^{*}\right) \pi^{J}\left(c^{U} \mid c^{M}\right)+\left(1-\alpha_{M}^{*}\right) \alpha_{Z}^{*}\left[\left(1-\beta^{*}\right) \pi^{S}\left(c^{U} \mid \underline{c}\right)+\beta^{*} \pi^{J}\left(c^{U} \mid \underline{c}\right)\right]=0 .
$$

Moreover, out of equilibrium, according to banks' beliefs either the application for $\underline{c}$ or the application for $c^{U}$ are accepted with a probability equal to 1 by bank $b$, with $b \in\{1,2,3\}$. In both cases, the same argument developed above, showing that bank $b^{\prime}$, with $b^{\prime} \in\{1,2,3\}$ prefers not to accept applications when one of its competitors issues $\underline{c}$ or $c^{U}$ and accept all applications, implies that not to accept any applications is rational also for bank 4.

\section{Step 3. Out-of-equilibrium beliefs are sequentially rational.}

Beliefs on the probabilities of out-of-equilibrium acceptances by banks making observable offers satisfy the PBE consistency requirement because these probabilities are "pinned down" by equilibrium strategies: all players believe that any bank deviating in $t=1$ follows its equilibrium strategy in $t=3$ and the latter is the optimal response to its competitors' equilibrium strategy.

Part (ii). In region $C$, there is no $P B E$ in which the entrepreneur undertakes the small project, and there is a PBE where the entrepreneur is not funded.

Both these results are immediate. First, in any equilibrium candidate where the entrepreneur undertakes the small project, a hidden lender (say, bank 3$)$ would earn a strictly positive profit by issuing $c_{3}=\left(x, r_{3}\right)$ with 
$r_{3}=\underline{r}+\varepsilon$ and $\varepsilon>0$, so that the remaining banks reject the application for their contracts, since the large project is not viable by assumption A6. Hence, there is no equilibrium where the entrepreneur is funded and undertakes the small project. Second, in the region under consideration there is an equilibrium with market freeze, where both banks 1 and 3 offer contract $\underline{c}$, but their acceptance rules are such that neither of them lends in equilibrium. This equilibrium outcome is supported by the following banks' strategies: banks 1 and 3 issue $\underline{c}$. Bank 1 accepts an application for this contract whenever this contract has not been issued by bank 2 as well. Bank 3 accepts an application for this contract whenever this contract has not been issued by bank 1 as well. The entrepreneur randomizes seniority with equal probability whenever two of his applications are accepted. But, since $\underline{r}>r^{M}=y_{S}$, the entrepreneur will not sign $\underline{c}$ if only one bank is ready to accept his application for this contract. The details of these proofs are straightforward and therefore are omitted.

Strategies under information sharing. The difference between a setting where banks do not share information and one where they do, is that in the latter they can condition their acceptances on the entrepreneur's past credit history, that is, on his total indebtedness and its breakdown across loans. Formally, each bank, say bank $b$, can condition its acceptance policy not only upon the contracts issued by banks making observable offers, but also upon the entrepreneur's total past indebtedness $R$. Hence, bank $b$ 's strategy is now defined by a loan contract $c_{b}$, an acceptance policy $\alpha: \mathbf{C} \rightarrow[0,1]$ (where, as before, $\mathbf{C}$ is the set of pairs of contracts issued by banks 1 and 2, while $\mathbf{c}$ is a particular element of $\mathbf{C}$ ), and a bound on the maximal total past indebtedness $R_{b} \geq 0$, chosen by the bank $b$, that the entrepreneur must not exceed to be eligible for contract $c_{b}$ at $t=3$.

In characterizing equilibria with information sharing, we assume that the entrepreneur's strategy satisfies the following individual rationality property $\tilde{S}^{E}$ stated below. Let $C^{E}$ be the set of contracts whose application has been accepted by some bank, and let $\tilde{C}^{E}$ be the set of all possible pairs of contracts in $C^{E} \cup c_{\emptyset} \cup c_{\emptyset}$ that the entrepreneur can obtain given the past indebtedness constraints imposed by banks issuing contracts in $C^{E}$. Then the entrepreneur's strategy has property $\tilde{S}^{E}$ if he behaves as follows:

(i) at stage 2, he applies to all banks;

(ii) at stage 3, he signs only one contract $c_{b} \in C^{E}$ if $r_{b} \leq r^{M}, r_{b} \leq r_{b^{\prime}}$ $\forall b^{\prime} \neq b, r_{b}<r_{b^{\prime \prime}} \forall b^{\prime \prime}<b$, and

$$
\mathrm{E}\left[u_{S}\left(\tilde{w}, r_{b}\right)\right] \geq \mathrm{E}\left[u_{L}\left(\tilde{w}, r_{b}, r_{b^{\prime}}\right)\right], \quad \forall c_{b^{\prime}} \in C^{E} ;
$$


(iii) signs no contract if $r_{b}>r^{M} \forall c_{b} \in C^{E}$ and

$$
\mathrm{E}[\tilde{w}]=1 \geq \mathrm{E}\left[u_{L}(\tilde{w}, \mathbf{r})\right],
$$

for all pair of contracts $\mathbf{c}=\left(c_{b}, c_{b^{\prime}}\right) \in \tilde{C}^{E}$;

(iv) signs the pair of contracts $\left(c_{b}, c_{b^{\prime}}\right) \in \tilde{C}^{E}$ if:

$$
\mathrm{E}\left[u_{L}\left(\tilde{w}, r_{b}, r_{b^{\prime}}\right)\right] \geq \mathrm{E}\left[u_{L}(\tilde{w}, \mathbf{r})\right], \quad \forall \mathbf{c} \in \tilde{C}^{E},
$$

and if $r_{b^{\prime \prime}}>\max \left\{r_{b}, r_{b^{\prime}}\right\}$ for $b^{\prime \prime}<\min \left\{b, b^{\prime}\right\}$;

(v) whenever indifferent between signing one contract and undertaking the small project, or signing two contracts and undertaking the large project, the entrepreneur chooses the small project.

Proof of Proposition 5. We show that under information sharing, the region of parameters $A^{\prime} \cup B^{\prime}$ features an unique PBE. In this equilibrium, only one bank issues $c^{*}=\left(x, r^{*}\right)$, with $c^{*}=c^{P C}$ in region $A^{\prime}$, lends to the entrepreneur, who undertakes the small project. The strategy profile that supports this equilibrium outcome is as follows.

Banks'strategies. At $t=1$, banks 1 and 2 issue $c^{*}$ and set $R_{1}=R_{2}=0$, banks 3 and bank 4 issue $\underline{c}$ and set $R_{3}=R_{4}=r^{*}$. Acceptance rules at $t=3$ are defined as follows: for all $b, \alpha_{b}=1$ if $c_{b}=\left(x, r_{b}\right)$ with $r_{b}>r^{*}$ and $R_{b}=0 ; r_{b}>r^{*} \quad$ and $R_{b} \in[x, \bar{r}]$, with $\bar{c}=(x, \bar{r}) \quad$ such that $\pi^{J}\left(c_{b} \mid \bar{c}\right)=0 ; \alpha_{b}=0$ otherwise.

Entrepreneur's strategy. The entrepreneur's strategy satisfies property $\tilde{S}^{E}$ above. Moreover, whenever the entrepreneur signs two contracts with banks $b$ and $b^{\prime}$, respectively, and the constraints imposed by $R_{b}$ and $R_{b^{\prime}}$ allow him to freely assign the seniority, he visits first the bank with the lowest rate if the two banks have different rates, otherwise seniority is assigned to bank $b$ if and only if $b<b^{\prime}$.

Out-of-equilibrium beliefs. Out-of-equilibrium beliefs at stage $t=3$ are again passive: each bank believes that its competitors follow their equilibrium strategies for any possible pair $\mathbf{c}=\left(c_{1}, c_{2}\right)$ of observable contracts.

Existence. We start by proving the existence of a PBE supported by the strategies and out-of-equilibrium beliefs described above. It is straightforward to verify that the entrepreneur's strategy is optimal. According to this strategy, the entrepreneur signs $c^{*}$ with bank 1 if all banks follow their equilibrium strategies. Hence, we need to show that no bank can profitably deviate either at $t=1$ or at $t=3$. We first show that 
banks' strategies are sequentially rational at $t=3$. First, for bank $b \in\{1,2,3,4\}$ it is rational to refuse application for $c_{b}=\left(x, r_{b}\right)$ if $r_{b}<r^{*}$. This is because, for any possible $\mathbf{c}=\left(c_{1}, c_{2}\right)$, according to bank $b$ 's outof-equilibrium beliefs, each hidden lender $\hat{b} \in\{3,4\}$ has issued $\underline{c}$ with $R_{\hat{b}}=r^{*}$, and accepts the application for such a contract with probability 1 for $R_{\hat{b}} \leq r^{*}$. Moreover, for $r>r^{*}$ choosing $\alpha_{b} \neq 0$ is rational for bank $b$ if and only if either $c_{b}=\left(x, r_{b}\right)$ with $r>r^{*}$ and $R_{b}=0$, or $r_{b}>r^{*}, x \leq R_{b} \leq \bar{r}$, with $\bar{c}=(x, \bar{r})$ such that $\pi^{J}\left(c_{b} \mid \bar{c}\right)=0$ : since beliefs are passive out of equilibrium, only in these cases bank $b$ makes nonnegative profits by accepting the entrepreneur's application. Moreover, sequential rationality at $t=3$ immediately implies that no bank can profitably deviate at $t=1$.

Finally, notice that in region $A^{\prime}, c^{*}=c^{P C}$ whenever $\phi \leq \phi^{\prime}(\sigma)$, as showed in the proof of Proposition 2.

Uniqueness. We now show that the PBE characterized above is unique in $A^{\prime} \cup B^{\prime}$. First, there cannot be a PBE where the entrepreneur signs the contract $c_{b}=\left(x, r_{b}\right)$, with $r_{b}<r^{*}$ with any bank $b$. This is immediate for region $A^{\prime}$ where $c^{*}=c^{P C}$. In region $B^{\prime}$, there is no equilibrium where any bank, say bank $b$, chooses $c_{b}=\left(x, r_{b}\right)$, with $r_{b}<r^{*}$ with $R_{b} \geq 0$ and $\alpha_{b}>0$. Indeed, if bank $b$ were to accept an application for $c_{b}$, a hidden lender-either bank 3 or 4 - could profitably issue $c^{\prime}=(x, \underline{r}+\varepsilon)$ with $\varepsilon$ such that

$$
\mathrm{E}\left[u_{L}\left(\tilde{w}, r^{\prime}, r_{b}\right)\right]>\mathrm{E}\left[u_{S}\left(\tilde{w}, r_{b}\right)\right]
$$

and accept the application for this contract with probability 1 regardless of the entrepreneur's past indebtedness, thus inflicting losses to bank $b$. Second, there cannot be a PBE where the entrepreneur signs $c_{b}=\left(x, r_{b}\right)$, with $r_{b}>r^{*}$, and undertakes the small project. This is because $c_{b}$ can be safely undercut by a bank offering a cheaper contract $c_{b^{\prime}}=\left(x, r_{b}-\varepsilon\right)$ with $\varepsilon$ small enough while requiring no past indebtedness $\left(R_{b}=0\right)$. Finally, it is immediate that in region $A^{\prime} \cup B^{\prime}$ there cannot be a $\mathrm{PBE}$ where the entrepreneur is rationed: this is because a hidden lender, say bank $\hat{b} \in\{3,4\}$, can profitably deviate by issuing $c_{\hat{b}}=\left(x, r^{*}+\varepsilon\right)$, and choosing $\alpha_{\hat{b}}=1$ and $R_{b}=0$.

Proof of Proposition 6. We first prove existence and then uniqueness.

Existence. We show that in the region of parameters under consideration there is a unique equilibrium with market freeze where banks have passive beliefs and equilibrium strategies are as follows.

Banks' strategies. At stage $t=1$, each bank $b$ issues $\underline{c}$ and sets $R_{b}=r_{M}$. At stage $t=3$, the acceptance policy is as follows: $\alpha_{b}=1$ if $c_{b}=\left(x, r_{b}\right)$, with 
$r_{b}>r^{M}, R_{b}=0$ and $\pi^{S}\left(c_{b} \mid \underline{c}\right) \geq 0$, or $r_{b}>r^{M}$ and $R_{b} \in[x, \bar{r}]$, with $\bar{c}=(x, \bar{r})$ such that $\pi^{J}\left(c_{b} \mid \bar{c}\right)=0 ; \alpha_{b}=0$ otherwise.

Entrepreneur's strategy. The entrepreneur's strategy satisfies the property $\tilde{S}^{E}$ defined above. Moreover, whenever the entrepreneur signs two contracts with bank $b$ and $b^{\prime}$, and the constraints imposed by $R_{b}$ and $R_{b^{\prime}}$ allow him to choose the seniority assignment, he gives seniority to the bank with the lowest rate if the two banks charge different rates, and otherwise randomizes with probability $1 / 2$.

Out-of-equilibrium beliefs. Out-of-equilibrium beliefs at $t=3$ are passive: each bank believes that its competitors follow their equilibrium strategies for any possible pair $\mathbf{c}=\left(c_{1}, c_{2}\right)$ of observable contracts.

Existence. It is easy to verify that the entrepreneur's strategy described above is optimal. Indeed, given the banks' equilibrium strategies, the entrepreneur can only fund the small project because, along the equilibrium path, no bank accepts applications by the entrepreneur when he is already indebted and the smallest rate at which the small project can be funded is $\underline{r}>r^{M}$. We need to show that no bank can profitably deviate either at $t=1$ or at $t=3$. First, we show that banks' strategies are sequentially rational at $t=3$. For bank $b \in\{1,2,3,4\}$ it is rational to refuse application for $c_{b}=\left(x, r_{b}\right)$ with $r_{b} \leq r^{M}$. This is because, for any possible $\mathbf{c}=\left(c_{1}, c_{2}\right)$, given bank $b$ 's beliefs, there is an hidden lender, say $\hat{b} \in\{3,4\}$, that issued $\underline{c}$ with $R_{\hat{b}}=r^{*}$, and accepts the application for this contract with probability 1 whenever $R_{\hat{b}} \leq r^{M}$. Moreover, for $r_{b}>r^{M}$ choosing $\alpha_{b} \neq 0$ is rational for bank $b$ if and only if $R_{b}=0$ and $\pi^{S}\left(c_{b} \mid \underline{c}\right) \geq 0$, or $r_{b}>r_{M}$ and $R_{b} \in[x, \vec{r}]$, with $\bar{c}=(x, \bar{r})$ such that $\pi^{J}\left(c_{b} \mid \bar{c}\right)=0$ : as beliefs are passive out of equilibrium, only in these two cases bank $b$ makes nonnegative profits by accepting the entrepreneur's application. Moreover, sequential rationality at $t=3$ immediately implies that no bank can profitably deviate at $t=1$.

Uniqueness. Suppose that there is a PBE in which the entrepreneur is funded. For all banks to at least break even, in this equilibrium the entrepreneur must get a loan of size $x$ and undertake the small project. Moreover, by individual rationality the entrepreneur's contract $c_{b}=\left(x, r_{b}\right)$ must charge a repayment $r_{b} \in\left[x, y_{S}\right]$. But in the region of parameters under consideration, all such contracts are vulnerable to opportunistic lending by a hidden bank $\hat{b} \in\{3,4\}$, which can profit by offering $c_{\hat{b}}=\left(x, r_{\hat{b}}\right)$, with $r_{\hat{b}}=2 x+\varepsilon$, and setting $R_{\hat{b}}=r^{M}$. Therefore, at least a hidden bank can profitably deviate from the equilibrium candidate. 


\section{References}

Attar, A., Campioni, E., and Piaser, G. (2006) Multiple lending and constrained efficiency in the credit market, Contributions to Theoretical Economics 6, 1-35.

Bar-Isaac, H. and Cuñat, V. (2012) Long-term debt and hidden borrowing. Unpublished Working paper. University of Toronto and London School of Economics.

Besanko, D. and Thakor, A. V. (1987) Collateral and rationing: sorting equilibria in monopolistic and competitive credit markets, International Economic Review 28, 1671-689.

Bernheim, B. D. and Whinston, M. D. (1986a) Menu auctions, resource allocations and economic influence, Quarterly Journal of Economics 101, 1-31.

Bernheim, B. D. and Whinston, M.D. (1986b) Common agency, Econometrica 54, 923-942.

Bester, H. (1987) Screening vs. rationing in credit markets with imperfect information, American Economic Review 75, 850-855.

Bisin, A. and Guaitoli, D. (2004) Moral hazard and non-exclusive contracts, RAND Journal of Economics 35, 306-328.

Bisin, A. and Rampini, A. (2006) Exclusive contracts and the institution of bankruptcy, Economic Theory 27, 277-304.

Bizer, D. S. and DeMarzo, P.M. (1992) Sequential banking, Journal of Political Economy 100, 41-61.

Brown, M., Jappelli, T., and Pagano, M. (2009) Information sharing and credit: firm-level evidence from transition countries, Journal of Financial Intermediation 18, 151-172.

Calzolari, G. and Pavan, A. (2006) On the optimality of privacy in sequential contracting, Journal of Economic Theory 130, 168-204.

de Janvry, A., McIntosh, C., and Sadoulet, E. (2010) The supply- and demand-side impacts of credit market information, Journal of Development Economics 93, 173-188.

Degryse, H., Ioannidou, V., and von Schedvin, E. (2011) On the non-exclusivity of loan contracts: an empirical investigation. Unpublished working paper, Tilburg University.

Detragiache, E., Garella, P., and Guiso, L. (2000) Multiple versus single banking relationships, Journal of Finance 55, 1133-1161.

Djankov, S., McLiesh, C., and Shleifer, A. (2007) Private credit in 129 countries, Journal of Financial Economics 84, 299-329.

Doblas-Madrid, A. and Minetti, R. (2013) Sharing information in the credit market: contract-level evidence from U.S. firms, Journal of Financial Economics 109, 198-223.

Farinha, L. A. and Santos, J. A. C. (2002) Switching from single to multiple bank lending relationships: determinants and implications, Journal of Financial Intermediation 11, 124-151.

Fudenberg, D. and Tirole, J. (1991) Game Theory, MIT Press, Cambridge, Massachusetts. Galindo, A. and Miller, M. (2001) Can credit registries reduce credit constraints? Empirical evidence on the role of credit registries in firm investment decisions. Unpublished working paper, Inter-American Development Bank and World Bank.

Gropp, R., Scholz, J. K., and White, M. J. (1997) Personal bankruptcy and credit supply and demand, Quarterly Journal of Economics 112, 217-251.

Herzberg, A., Liberti, J. M., and Paravisini, D. (2011) Public information and coordination: evidence from a credit registry expansion, Journal of Finance 66, 379-412.

Holmstrom, B. and Tirole, J. (1997) Financial intermediation, loanable funds, and the real sector, Quarterly Journal of Economics 112, 663-691.

Jappelli, T. and Pagano, M. (2002) Information sharing, lending and defaults: cross-country evidence, Journal of Banking and Finance 26, 2017-2045. 
Kahn, C. and Mookherjee, D. (1998) Competition and incentives with nonexclusive contracts, RAND Journal of Economics 29, 443-465.

La Porta, R., Lopez-de-Silanes, F., Shleifer, A., and Vishny, R. W. (1997) Legal determinants of external finance, Journal of Finance 52, 1131-1150.

Leitner, Y. (2012) Inducing agents to report hidden trades: a theory of an intermediary, Review of Finance 16, 1013-1042.

Longhofer, S. D. (1997) Absolute priority violations, credit rationing, and efficiency, Journal of Financial Intermediation 6, 249-267.

Martimort, D. and Stole, L. (2003) Contractual externalities in common agency games, Advances in Theoretical Economics 3, 1-40.

Martimort, D. and Stole, L. (2009) Market participation under delegated and intrinsic common agency games, RAND Journal of Economics 40, 78-102.

McAfee, R. P. and Schwartz, M. (1994) Opportunism in multilateral vertical contracting: nondiscrimination, exclusivity, and uniformity, American Economic Review 84, 210-230.

Miller, M. J. (2003) Credit reporting around the globe, in: M. J. Miller (ed.), Credit Reporting Systems and the International Economy, MIT Press, Cambridge, Massachusetts, 25-79.

Mookherjee, D., Ray, D., and Ghosh, P. (2000) Credit rationing in developing countries: an overview of the theory, in: D. Mookherjee and D. Ray (eds), A Reader in Development Economics, Blackwell, London, 283-301.

Ongena, S. and Smith, D. C. (2000) What determines the number of bank relationships? Cross-country evidence, Journal of Financial Intermediation 9, 26-56.

Padilla, A. J. and Pagano, M. (1997) Endogenous communication among banks and entrepreneurial incentives, Review of Financial Studies 10, 205-236.

Padilla, A. J. and Pagano, M. (2000) Sharing default information as a borrower discipline device, European Economic Review 44, 1951-1980.

Pagano, M. and Jappelli, T. (1993) Information sharing in credit markets, Journal of Finance 48, 1693-1718.

Parlour, C. and Rajan, U. (2001) Competition in loan contracts, American Economic Review 91, 1311-1328.

Petersen, M. and Rajan, R. G. (1994) The benefit of lending relationships: evidence from small business data, Journal of Finance 49, 1367-1400.

Segal, I. and Whinston, M. D. (2003) Robust predictions for bilateral contracting with externalities, Econometrica 71, 757-791.

Stiglitz, J. E. and Weiss, A. (1981) Credit rationing in markets with imperfect information, American Economic Review 71, 393-410.

White, M. J. (2006) Bankruptcy and consumer behavior: theory and evidence from the U.S., in: G. Bertola, R. Disney, and C. Grant (eds), The Economics of Consumer Credit, MIT Press, Cambridge, Massachusetts, pp. 239-274.

Williamson, S. D. (1987) Costly monitoring, loan contracts, and equilibrium credit rationing, Quarterly Journal of Economics 102, 135-146. 